\title{
Urbanismo crítico, cartografía y evolución del verde urbano en los planes de ensanche históricos de la ciudad de Palma (Mallorca)
}

\author{
Gabriel Alomar-Garau ${ }^{1}$
}

Recibido: 23-11-2019 | en su versión final: 22-10-2020

Resumen En el presente trabajo se realiza un examen detallado de la planificación del verde urbano en los tres planes de ensanche históricos de Palma (Calvet, 1901; Bennazar, 1917; Alomar, 1943), con la finalidad de esclarecer la génesis y el ulterior desarrollo de los principales parques y jardines públicos de la ciudad, además del arbolado viario. Se analiza el germen de estos tres planes, su contenido en relación con la matriz verde urbana y las características primitivas del espacio a urbanizar, así como la crítica urbanística que suscitaron los proyectos de ensanche y de reforma antes y después de su aprobación. El marco teórico y conceptual del que parte este trabajo es el de los ensanches españoles, de raíz decimonónica, y específicamente los ejecutados en la ciudad de Palma, en los cuales el planeamiento de la infraestructura verde y su progreso formal han sido aspectos apenas estudiados. Mediante un método de trabajo de consulta directa a las fuentes, la revisión detallada de las memorias de esos planes y de sus planos respectivos ha permitido reunir en un mapa de síntesis la trama urbana resultante y su matriz verde, para contrastarla con la realidad urbana actual. El resultado es la constatación de la desfiguración y desnaturalización de las áreas verdes inicialmente programadas, aunque a partir de 1973, en los sucesivos planes generales de ordenación urbana -sobre todo el de 1985- se aprecia un renovado interés por la restitución del verde en la ciudad y su planificación rigurosa como estrategia de regeneración urbana con criterios ambientalistas y de sostenibilidad.

Palabras clave: planeamiento urbano; espacios libres públicos; morfología urbana; paisaje urbano

Citación

Alomar-Garau, G. (2021). Urbanismo crítico, cartografía y evolución del verde urbano en los planes de ensanche históricos de la ciudad de Palma (Mallorca). ACE: Architecture, City and Environment, 15(45), 9039. DOI: http://dx.doi.org/10.5821/ace.15.45.9039

\section{Critical Urban Planning, Mapping and Evolution of the Urban Green in the Historic Expansion Plans of the City of Palma (Majorca)}

Abstract

\begin{abstract}
This paper examines the urban green planning in the three historical expansion plans of Palma (Calvet, 1901; Bennazar, 1917; Alomar, 1943), with the finality to clarify the genesis and subsequent development of the main parks and gardens public areas of the city, in addition to the road trees. The germ of these three plans is also analyzed, their content in relation to the urban green matrix, and the primitive characteristics of the space to be developed, as well as the urban criticism that the expansion and reform projects raised before and after their approval. The theoretical and conceptual framework from which this work starts is that of the nineteenth-century extensions of Spanish cities, and specifically those executed in the city of Palma, whose green infrastructure and its formal progress have been aspects that have been little studied. Using a working method of direct consultation with the sources, the detailed review of the memories of these plans and their respective plans has allowed to gather in a synthesis map the resulting urban layout and its green matrix, to contrast it with the current urban reality. The result is the verification of the disfigurement and denaturalization of the initially programmed green areas, although from the year 1973, in the successive general urban planning plans -especially that of 1985-, there is a renewed interest in the restoration of green areas in the city and its rigorous planning as an urban regeneration strategy with environmental and sustainability criteria.
\end{abstract}

Keywords: urban planning; public free spaces; urban morphology; urban landscape

1 Doctor en Geografía. Profesor de la Universitat de les Illes Balears. Director del Máster en Paisaje y Restauración (ORCID: 0000-0003-0101-5944, WoS ResearcherID: AAB-5199-2019). Correo de contacto: gabriel.alomar@uib.es 


\section{Introducción}

En el presente trabajo se revisa la planificación del verde urbano en los tres planes de ensanche históricos de la ciudad de Palma (Calvet, 1901; Bennazar, 1917; Alomar, 1943), así como su materialización práctica y su ulterior desarrollo. Aunque cada uno de estos planes adoptó distintas denominaciones -Proyecto de Ensanche, Plan de Reforma, Plan de Extensión, respectivamente-, los tres pueden considerarse 'de ensanche' en la medida en que en ellos se acomete el crecimiento urbanístico extramuros de la ciudad, general o parcial, y no son planes generales de ordenación tal como éstos fueron instaurados por la Ley del Suelo de 1956. En el trabajo también se hace una revisión de la crítica urbanística que suscitó la urbanización del ensanche antes y después de la aprobación de esos planes y de ciertos proyectos y anteproyectos de urbanización, aunque no siempre llegaran a ejecutarse. Ciertamente, el ensanche de Palma ha sido objeto de no pocos estudios de diversa índole (Cantarellas, 1981; Ladaria, 1992; Delgado, 1995; Seguí, 1985, 1990 y 2000), y en su momento fue objeto de crítica por parte de los mismos urbanistas que firmaron nuevos planes de extensión o ciertas operaciones urbanísticas a finales del siglo XIX y durante la primera mitad del siguiente (Ferrà, 1891; Bennazar, 1917; Forteza, 1921, 1931 y 1934; Alomar, 1950).

En los trabajos referidos al primer desarrollo urbanístico extramuros de Palma, el tema de los espacios libres, y dentro de éste el verde urbano, no ha sido explorado en detalle o bien se ha hecho de forma muy fragmentaria. Para intentar cubrir esta carencia, nuestro trabajo comienza por reconocer la estructura morfológica de la ciudad y las transformaciones del espacio extramuros que supuso la ejecución del primer plan de ensanche, presentado por el ingeniero ibicenco Bernardo Calvet Girona en el año 1897, y aprobado en 1901. De él es heredero directo el trazado radioconcéntrico actual, así como también alguno de los principales espacios verdes de la ciudad ampliada. A continuación, se repasan críticamente los planteamientos teóricos y la realización de la matriz verde de Palma tal como se consigna en este primer plan. Lo mismo se hace para el caso del segundo plan -en realidad, un plan de reforma parcial firmado en 1917, que no se llegó a ejecutar-, obra del arquitecto municipal Gaspar Bennazar Moner, así como para el tercer y último plan, presentado por el arquitecto Gabriel Alomar Esteve en 1941 y aprobado en 1943. Éste último tuvo un grado de ejecución mucho menor que el de Calvet, y apenas modificó en el ensanche la trama urbana heredada. De estos tres proyectos se abordan los presupuestos teóricos ambientalistas, higienistas y estéticos de los que partieron para promover y situar el verde en la ciudad. Para esto, el método de trabajo ha consistido en la consulta a las fuentes documentales originales de los planes mencionados, cuyo análisis ha permitido comprobar esos presupuestos. Además de estos proyectos, se repasan brevemente aquellos planes generales de ordenación -es decir, no planes de ensanche o de reforma de este- en virtud de los cuales se acabó conformando el espacio urbano que define la ciudad de Palma en su totalidad: el Plan General de Ordenación Urbana del año 1964, y los que le siguieron en 1973, 1985 y 1998. Aunque cada uno de estos planes de ordenación merecerían una atención detallada, esto redundaría en un esfuerzo investigador que excede nuestros objetivos.

Las referencias a las zonas verdes en los planes de ensanche decimonónicos españoles son una tónica común, pues en ellos se expresaban las teorías naturalistas en boga -amor a la naturaleza- y las higienistas -valoración del aire y de la luz solar-. Si en los siglos ilustrados del XVII y el XVIII al verde urbano se le asignaba unos fines decorativos y arquitectónicos -estéticos, en definitiva-, en el XIX los fines serán ambientalistas, pues lo que se pretende con la organización urbana de las zonas con vegetación es higienizar la ciudad. Al respecto, son bien conocidas las ideas de Olmsted y Necklace para la ciudad de Boston, cuando en 1878 planea un sistema de parques urbanos conectados mediante corredores. En 1898, el británico Ebenezer Howard se referirá a las ciudadesjardín, que conceptualmente se apoyaban en el urbanismo utópico de la primera mitad del XIX, que abogaba por una ciudad entendida como comunidad perfecta y autosuficiente. También se apoyaban en la idea de la vivienda unifamiliar con jardín, cuyo precedente se encontraba en la vida victoriana de la segunda mitad del XIX, y con la que se buscaba conciliar la cultura urbana con el mundo rural.

ACE, 15 (4.5) CC BY-ND 3.0 ES | UPC Barcelona, España | Urbanismo crítico, cartografía y evolución del verde urbano en los planes de ensanche históricos de la ciudad de Palma. DOI: http://dx.doi.org/10.5821/ace.15.45.9039 
Ahora bien, si la ciudad-jardín tiene como objeto ser una comunidad autosuficiente, será la ciudadjardín satélite, conceptualizada por Ernest Simon (Ward, 2017), la que se situará cerca de la gran ciudad en la que trabajan los habitantes de un núcleo satélite. En realidad, las ciudades-jardín en España no se generalizarían más que como "una forma alternativa de organización del espacio: la que resulta de la utilización sistemática de la vivienda unifamiliar con huerto o jardín” (Terán, 1996, pág. 172). En Mallorca, el urbanismo inglés y las ideas de Howard tuvieron una cierta repercusión, y durante el siglo XX se planificaron unos pocos emplazamientos turísticos cuyos planteamientos teóricos eran los mismos que los del inglés, aunque su plasmación práctica frustrase la teoría: Palma Nova (1934), según un proyecto del arquitecto José Goday, o la playa de Alcúdia (1934), obra del arquitecto norteamericano Arthur Middlehurts. Además de estos proyectos podemos mencionar el plan parcial del arquitecto Gabriel Alomar Esteve, de 1958, para una 'ciudad jardín turística mediterránea' en Son Verí de Marina (Horrach, 2013), en el sector oriental de la Playa de Palma.

En lo que se refiere al urbanismo de los ensanches en España, hay que recordar que el planeamiento urbano, surgido de la necesidad de ordenar el crecimiento de las ciudades, aparece tardíamente en el siglo XIX. Antes, las normas que regulaban el funcionamiento y desarrollo de la ciudad estaban en manos de los ayuntamientos, cuyas Ordenanzas Municipales tutelaban aspectos como el ornato y la salubridad (Andrés, 1999). También hay que recordar que el concepto de ensanche y la necesidad de administrar el espacio urbano aparece al amparo de las Leyes españolas de Ensanche de 1864, 1876 y 1892. A éstas hay que unir la Ley de Expropiación Forzosa de 1879 y la Ley de Saneamiento y Reforma Interior de las Poblaciones, de 1895. Para el caso de Palma, esta última es quizá la más importante, pues es la que propició el derribo de las murallas -incompleto, pues hoy se conserva un tramo amurallado litoral y los baluartes marítimos - y a la sazón la posibilidad de acometer la extensión extramuros. Según García-Bellido (2006, pág. 12), derribos como el del recinto amurallado de Palma constituyeron "el más decisivo acontecimiento de trascendencia territorial", pues "entra en resonancia en todos los países casi a la vez, como el punto de inflexión e inicio del fin de una larga era de varios miles de años de urbanismo constreñido por las ciudades sucesivamente amuralladas". También es de fines del XIX la legislación española en materia de espacios verdes -en concreto, de parques y jardines-, que otorgaba a los municipios licencia para su creación y su mantenimiento. No en vano, en palabras de Ladaria (1992, pág. 37), "el desarrollo de la legislación urbanística se produce como una reacción contra los males de las ciudades", males que en Palma no eran otros que la contaminación de los aljibes, el relativo hacinamiento de sus habitantes en el casco urbano intramuros, y sus efectos en la mortalidad debida a enfermedades infecciosas (en 1865 se consigna una primera epidemia de cólera).

Los espacios verdes urbanos son, en rigor, espacios abiertos libres de edificación, con presencia de vegetación, que cumplen unas funciones de espacio público de ocio al aire libre. El verde urbano al que se refiere el presente trabajo comprende tales espacios (parques, jardines y plazas vegetadas), al margen de la vegetación que aparece en los viales en forma de arbolado viario. De acuerdo con Gilbert (1991), los paisajes urbanos pueden clasificarse en tres tipos sucintos: los estrictamente tecnológicos o artificiales, los ajardinados (que necesitan una gestión constante) y los ecológicos (en donde la vida silvestre es autónoma y la gestión requerida es mínima). En relación con los segundos -los parques o jardines públicos urbanos-, García-Lorca (1989) les atribuye cinco funciones primordiales: función recreativa o de esparcimiento, función ambiental, función higiénico-sanitaria, función estética y función didáctico-educativa. En un marco global de cambio climático, la función ecológica o ambiental ha sido prestigiada por los efectos de moderación de las temperaturas atribuidos a las cubiertas vegetales, sobre todo en los sectores de la ciudad donde la intensidad del fenómeno de isla de calor urbana es más elevada (Ochoa, 2009). También ha sido prestigiada por el papel de la vegetación como purificadora del aire, al sustraer ozono troposférico y capturar de $\mathrm{CO}_{2}$ atmosférico (Nowak et al., 2000; Priego, 2011). En este punto podemos recordar la popular metáfora de los parques verdes como 'pulmones' de la ciudad, atribuida a William Pitt y mencionada en 1808 en un debate del parlamento británico, aunque fue el arquitecto paisajista escocés John Loudon

ACE, 15 (4.5) CC BY-ND 3.0 ES | UPC Barcelona, España | Urbanismo crítico, cartografía y evolución del verde urbano en los planes de ensanche históricos de la ciudad de Palma. DOI: http://dx.doi.org/10.5821/ace.15.45.9039 
(1783-1843) quien primero desarrollara la analogía entre la mecánica de la ciudad y el funcionamiento del cuerpo, y el primero en reclamar, en 1803, la creación de parques públicos como antídoto contra los males de la polución industrial (Crompton, 2017).

Desde entonces, es amplísima y variada la bibliografía internacional relativa al verde urbano, tanto en lo que se refiere a su planificación (Sukopp y Werner, 1989), a su eficacia refrigeradora allí donde se detectan islas de calor urbanas (Bowler et al., 2010; Salvati et al., 2016; Alomar-Garau y Llop-Garau, 2018) o a la representación y clasificación cartográfica de la estructura espacial y volumétrica de la vegetación mediante datos LiDAR (Anderson et al., 2018; Alomar-Garau y Bauzà-Llinàs, 2020), entre otros muchos aspectos. También son interesantes y no menos importantes los análisis de percepción humana de la vegetación urbana en clave paisajística y estética, como hacen Hoyle et al. (2017) para ocho localizaciones en Inglaterra. Fruto de esta variedad de estudios, en España la infraestructura verde ha sido investigada con distintos objetivos, como el que se refiere al desarrollo práctico de los espacios verdes en ciertas ciudades españolas (Muga, 1980; Gómez-Lopera, 2005, entre otros), la cuantificación de la diversidad vegetal (Dana et al., 2002) o el vínculo entre los precios de la vivienda y la dotación de zonas verdes (Bengochea, 2003). También en España, aspectos teóricos relativos al verde urbano han merecido las consideraciones de autores como Alonso (1971), Rodríguez-Avial (1980); García-Lorca (1989); Salvo y García-Verdugo (1994), Santiago (2008) o Fadigas (2017), entre otros.

\section{Palma y sus planes de ensanche: aspectos morfológicos}

En términos generales, Palma constituye una ciudad mediterránea residencial, de servicios, administrativa y de negocios, que hoy opera como centro de un sistema urbano más amplio de producción de servicios turístico-comerciales. Según datos del Padrón publicados por el Institut d'Estadística de les Illes Balears (IBESTAT, 2020a), el término municipal tenía en el año 2019 un tamaño poblacional de 409.065 habitantes, mientras que la ciudad propiamente dicha, cuyos límites podemos establecer en el semicírculo de la vía de circunvalación conocida como Vía de Cintura, sumaba 272.880 habitantes (el 66,7 \% del total municipal), siendo sus características las de una ciudad media. A grandes rasgos, su estructura la conforman dos cinturones de ronda concéntricos: el primero e interior ocupa el trazado de las antiguas murallas, y hoy es conocido con el nombre de las Avenidas; el segundo y exterior es el de la mencionada Vía de Cintura, que conforma los límites exteriores de la segunda corona del ensanche (Figura 1).

Así conformada, la ciudad propiamente dicha totaliza un área de unos $18 \mathrm{~km}^{2}$ (1.800 Ha), y puede ser dividida, aunque con matices, en tres grandes piezas urbanas. La primera es la del antiguo casco histórico intramuros, de trazado básicamente medieval y por tanto irregular, con calles estrechas e intrincadas y una alta densidad edificatoria. Las murallas que cerraban este casco comenzaron a construirse en 1575, cuando en el Renacimiento se generaliza el uso militar de la artillería, que exige reforzar el recinto defensivo con baluartes, hornabeques, revellines y otras estructuras de defensa, lo que supuso una sustanciosa ampliación del recinto amurallado, cuya construcción se dio por completada entre 1801 y 1805 (Cantarellas, 1981, pág. 104). La segunda pieza es la del primer ensanche de la ciudad, radioconcéntrico, constituido por edificios de distintas etapas y tipologías arquitectónicas del siglo XX. La tercera pieza es la constituida por las diversas y sucesivas promociones urbanísticas que hacia finales del XX organizaron el segundo ensanche, y que han ido colmatando el espacio urbanizado hasta la ya mencionada vía de circunvalación. Si antes de 1902 las murallas renacentistas ejercían una función de limitación física del crecimiento de la ciudad, hoy esta demarcación la ejerce ese otro muro - no de sillares de piedra arenisca sino de hormigón- constituido por la Vía de Cintura.

ACE, 15 (4.5) CC BY-ND 3.0 ES | UPC Barcelona, España | Urbanismo crítico, cartografía y evolución del verde urbano en los planes de ensanche históricos de la ciudad de Palma. DOI: http://dx.doi.org/10.5821/ace.15.45.9039 
Figura 1. Palma: Síntesis de los planes de ensanche y de reforma históricos

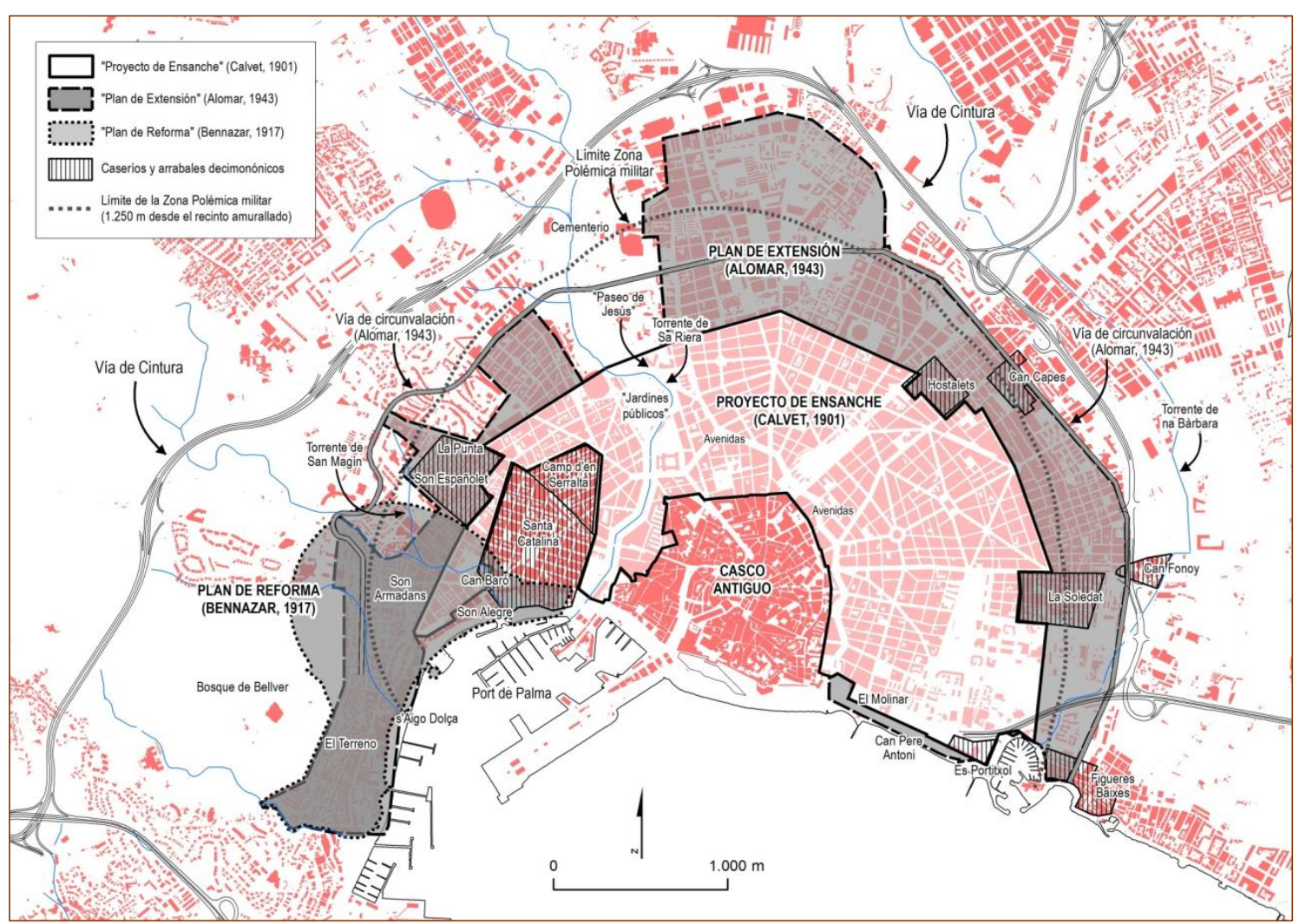

Fuente: Elaboración propia a partir de los planos históricos originales de ensanche y reforma, sobre la base cartográfica del Mapa Topográfico de las Islas Baleares de 2006, de escala 1:5.000.

\subsection{El 'Proyecto de Ensanche' de Calvet (1901)}

La pieza que constituye la urbanización del primer ensanche se ejecutó según el 'Proyecto de Ensanche' presentado por Bernardo Calvet en 1897, y del que es heredero el trazado urbano actual de la primera ciudad extramuros. El proyecto fue aprobado en 1901, años después de que, en 1873, el Gobierno de la República española hubiese decretado el derribo del recinto amurallado de Palma, y en 1896 fuese sacado a concurso el proyecto de un ensanche. Esta fecha indica, en comparación, el gran retraso con que Palma se sumaba a las operaciones de ensanche impulsadas con anterioridad en otras ciudades españolas, “una tarea típicamente decimonónica” (Cantarellas, 1981, pág. 479). El proyecto adjudicado se proponía urbanizar una corona circular de 393,6 Ha alrededor del casco histórico intramuros -el cálculo es del propio Calvet-, corona que había de absorber buena parte de los caseríos periféricos preexistentes. La nueva urbanización se ciñó al espacio constituido por la antigua zona de servidumbre militar, la denominada 'zona polémica' -pólemos, en griego clásico, significa guerra-, servidumbre que en Palma alcanzaba un radio de 1.500 varas castellanas, equivalentes a unos $1.250 \mathrm{~m}$, contadas a partir del recinto amurallado, y dentro del cual existían fuertes restricciones edificatorias (Figura 1). Como forma de sortear estas restricciones, durante el siglo XIX fueron creándose en torno a los límites de la 'zona polémica' ciertos núcleos urbanos de carácter residencial o fabril, dando al conjunto de la ciudad decimonónica un aspecto polinuclear, con un núcleo central macrocéfalo constituido por el casco intramuros. La ciudad ensanchada posterior, afectada por las transformaciones derivadas de la ejecución del plan de Calvet, será fisionómica y substancialmente diferente.

ACE, 15 (4.5) CC BY-ND 3.0 ES | UPC Barcelona, España | Urbanismo crítico, cartografía y evolución del verde urbano en los planes de ensanche históricos de la ciudad de Palma. DOI: http://dx.doi.org/10.5821/ace.15.45.9039 
El plan de Calvet se apartaba de las propuestas urbanísticas realizadas para ciudades como Madrid (Castro, 1860) o Barcelona (Cerdà, 1855), en las que se apostaba por la planta rectangular (Magrinyà, 2009), mientras que para Palma se proponía una organización de la trama urbana a partir de vías radiales de circulación, que no eran sino la prolongación hacia el centro de la ciudad de las carreteras que comunicaban Palma con ciertas poblaciones del resto de la isla: Valldemossa, Sóller, Inca, Manacor, Llucmajor. En el espacio entre estas vías, las manzanas adquirían un aspecto trapezoidal. Por eso, en el ensanche de Calvet el trazado de las principales arterias determina la forma final de las manzanas, al contrario de lo que ocurre en el caso del plan de Cerdà para la ciudad de Barcelona, en el que son las manzanas las que determinan el trazado viario. Hay que decir que al concurso de ensanche se habían presentado dos proyectos: el ganador de Calvet, presentado con el lema Felix qui potuit cognoscere causas (locución latina extraída de les Geórgicas del poeta Virgilio: Geórgicas, II, 489, y que se traduce como "feliz aquel que puede conocer las causas de las cosas"), y el perdedor, presentado con el lema Salus populi (locución latina que se traduce corrientemente como "salud -o bienestar- del pueblo", pero que proviene del lema latino completo salus populi suprema lex est: "la salvación del pueblo es ley suprema" o "por encima de todas las leyes está la salud del pueblo"). Este último proyecto, probablemente de Pedro García Faria y Francisco de Paula Oliver Rolandi (Miranda, 2006), muestra grandes similitudes con el plan de ensanche de Barcelona de Idelfonso Cerdà, pues el plan de García Faria también despliega una trama urbana ortogonal con manzanas achaflanadas. Además, basa la orientación de las calles en aquella orientación a priori más higiénica, que es la que coincide con el eje SO-NE, el mejor ventilado, pues es el eje que en Palma adopta, respectivamente, la brisa marina diurna y la brisa de tierra nocturna. En el proyecto Salus populi se proponía una magna zona verde de unas 17 hectáreas, en cuyo plano aparece indicada como "Parque Proyectado" (Figura 4d), situada entre una parte de lo que hoy es el barrio del Camp d'en Serralta, al oeste del actual Paseo de Mallorca, y una parte del barrio de Es Fortí, es decir en el antiguo Hornabeque.

En relación con los mencionados núcleos suburbiales decimonónicos, su aparición desordenada y mediante simples planos de alineaciones no resulta extraña, pues hasta la aprobación de la primera ley española de Régimen del Suelo, en 1956, los ayuntamientos no disponían de los medios legales adecuados para controlar los procesos urbanizadores producidos en la periferia del primer y el segundo ensanche. Algunos de esos núcleos han mantenido en parte su morfología urbana y su arquitectura original, pues no todos se vieron afectados por el crecimiento urbanístico y edificatorio que llevó aparejado el crecimiento poblacional motivado por la creciente actividad turística a partir de la década de los 50 del siglo XX. Los caseríos eran bien de carácter típicamente industrial y para Las clases populares (Hostalets, La Soledat, El Molinar, Can Capes, San Onofre, Can Pere Antoni, El Portitxol y las Figueres Baixes), bien de carácter residencial o de recreo (Son Alegre, La Vileta, Son Serra, Son Españolet, La Punta, El Terreno y Portopí). Sólo en estos últimos Bernardo Calvet, en su Memoria del Proyecto de ensanche de la Ciudad de Palma de Mallorca, distingue "un sello patriarcal de calma, beatitud, lujo, comodidad y falta de industria y comercio” (Calvet, 1897, pág. 52). El arrabal de Santa Catalina, al oeste de la ciudad y junto al recinto amurallado, puede decirse que constituyó de facto el primer ensanche oficial de la ciudad en virtud de una Real Orden de 1869 (Santaner, 1967; Mansergas, 2015). Si Calvet repudia el desorden constructivo de los arrabales exteriores, hace una excepción con los de Santa Catalina y el Camp d'en Serralta, proyectados por el Cuerpo de Ingenieros Militares, y en los que ve "lo mejor de Palma, a pesar de las privaciones que en alturas y gruesos de muros impusieron las zonas polémicas” (Calvet, 1897, pág. 47). Hay que decir que una parte significativa de los bordes del suelo urbano de Palma era propiedad de la clase dominante mallorquina, que presionó para que en Santa Catalina se dejase construir dentro de la 'zona polémica' sin apenas necesidad de planos, aunque el Ramo militar se opusiera a ello. En el caso singular de El Terreno, se trata de la primera barriada residencial de Palma, que como tal se remonta al siglo XVIII y a la vocación ilustrada de sus primeros propietarios, aunque su primer plan reglado de urbanización es de 1856.

ACE, 15 (4.5) CC BY-ND 3.0 ES | UPC Barcelona, España | Urbanismo crítico, cartografía y evolución del verde urbano en los planes de ensanche históricos de la ciudad de Palma. DOI: http://dx.doi.org/10.5821/ace.15.45.9039 
Por otra parte, hay que recordar que a finales del XIX el crecimiento poblacional era mayor en el conjunto de los arrabales extramuros que dentro de la ciudad intramuros, tal como indica Calvet en su Memoria (1897): entre 1840 y 1887, es decir en un periodo de 47 años, la población de la Palma intramuros había crecido poco menos del 27 \% (en 1840 contaba con 32.994 habitantes y en 1887 con 41.649), mientras que la población de la Palma extramuros había aumentado poco más de un $154 \%$ (en 1840 contaba con 7.411 habitantes y en 1887 con 18.865). Así, en términos demográficos, si la ciudad intramuros crecía a mucho menor ritmo que la de los núcleos periféricos era porque la primera apenas podía contener más gente. La paralización de todo intento de urbanización extramuros en virtud del uso militar preferente de los terrenos de la 'zona polémica', había sido la causa del relativo confinamiento de la población dentro del antiguo casco urbano, que redundó en una merma adicional de las condiciones de salubridad debida a la falta de redes de agua y alcantarillado, merma que sirvió de alegato para promover la urgente necesidad de un ensanche. Su objetivo no era otro que ampliar el suelo urbanizable para dar salida al aumento poblacional y su relativo apiñamiento dentro de la ciudad intramuros. Según los censos históricos de población proporcionados por el Institut d'Estadística de les Illes Balears (IBESTAT, 2020b), en 1897, año en que se está gestando el primer plan de ensanche, la población de Palma -sin Establiments- era de 62.525 habitantes. En 1900 era de 63.937 habitantes. Calvet planifica su ensanche para un horizonte de 25 años, momento en el que calcula que la ciudad habrá alcanzado los 124.000 habitantes. Esta proyección no se cumplió, pues en 1920 Palma alcanza los 77.418 habitantes, y 88.262 en 1930 (de éstos, en este año sólo 11.969 vivían en el nuevo espacio del ensanche). En 1940, año en que se gesta el nuevo plan de extensión de Alomar (1943), Palma totalizaba 114.405 habitantes, y 136.814 en 1950. Por tanto, las cifras de población previstas por Calvet para el año 1925 se alcanzaron unos veinte años más tarde de esta fecha.

En relación con la 'zona polémica' dentro de cuyo perímetro debía desplegarse la urbanización de la nueva ciudad extramuros, en 1879 el Ayuntamiento de Palma había encargado a Pedro de Alcántara Peña la realización de un plano topográfico cuya finalidad fuese la de servir de base a los anteproyectos del futuro ensanche (Alomar, 1950; Cantarellas, 1984; Ladaria, 1992). En ese plano debía consignarse el límite territorial pactado con el Ministerio de la Guerra, coincidente con los límites de la zona de servidumbre militar. El plano de Alcántara Peña, de escala 1:2.000, se levantó entre 1879 y 1896, y el radio de servidumbre no aparece consignado como tal, aunque sí mediante una línea de color rojo con la indicación "Límite del Ensanche de Palma". El único plano histórico de la ciudad en el que hemos podido constatar el dibujo de este radio es el de Josef de Font, manuscrito y coloreado, del año 1800 (Tous, 2009). En este plano, el radio delimitador viene indicado por una línea discontinua acompañada por la expresión "Línea que demarca la distancia de 1500 varas de la Plaza". La "Plaza" en cuestión no era otra que la plaza fuerte o plaza militar que entonces constituía la ciudad amurallada de Palma. Esta condición era la que, precisamente, paralizaba todo intento de urbanización del espacio extramuros, lo que acabó confinando la población en el casco urbano intramuros, en su sentido más acusado de cerramiento. En el plano de Font también aparecen dibujadas las casas y edificios ya construidos dentro de la 'zona polémica', es decir las construcciones que, según las Ordenanzas del Ejército, acaso incumplían la ley. Según una relación del año 1883, el número de edificios extramuros era entonces de 1.895 (Cantarellas, 1981, pág. 485). Entre esas construcciones se encontraban los predios rurales que rodeaban la ciudad -las possessions, según la denominación local mallorquina-, y que con el tiempo serían absorbidas por el ensanche: Son Olivera, El Rafal, Son Cotoner, Son Pizà, Son Bruy, Son Puigdorfila, Son Nadal, Son Tugores, etc.

Antes de finalizar el siglo XIX, no pocas voces se referirán a las murallas palmesanas como ese "obstáculo capital que se opone al desarrollo de Palma" (Calvet, 1897, pág. 50); ese símbolo de "los obstáculos que se oponen a nuestro progreso moral y material”, según la cita que Mayol (2010, pág, 15) recoge de un discurso de Miquel dels Sants Oliver, de homenaje al ingeniero Eusebio Estada (Oliver, 1893); o esa "inútil cinta de piedra que oprimiendo nuestra ciudad impide su desarrollo", según una cita de Ladaria (1992, pág. 47) recogida del legajo núm. 1068, carpeta núm. 1, fól. 3, del Archivo

ACE, 15 (45) CC BY-ND 3.0 ES | UPC Barcelona, España | Urbanismo crítico, cartografía y evolución del verde urbano en los planes de ensanche históricos de la ciudad de Palma. DOI: http://dx.doi.org/10.5821/ace.15.45.9039 
Municipal del Excmo. Ayuntamiento de Palma. La oportunidad del derribo de las murallas que había de permitir el crecimiento de la ciudad había empezado a tomar forma a mediados del XIX, y aduciéndose razones higiénicas y de presión demográfica se creó entre la población civil y en los organismos municipales un ambiente ciertamente virulento a favor del derribo. Fue el ingeniero de caminos y político mallorquín Eusebio Estada (1843-1917) quien en un libro capital publicado en 1885, La ciudad de Palma. Su industria, sus fortificaciones, sus condiciones sanitarias y su ensanche, había dado la argumentación clave según la cual la forma de mejorar las deficientes infraestructuras y condiciones sanitarias en Palma pasaba por el derribo del recinto amurallado, que entonces se tenía como el principal elemento constructivo que obstaculizaba el crecimiento de la ciudad, el advenimiento de la Revolución Industrial y, en definitiva, el ingreso de la sociedad palmesana en la modernidad. En la causa del derribo también participaron activamente el político y conde mallorquín Lluís de San Simón (1864-1938), Antonio Maura y el teniente general Valeriano Weyler (1838-1930), quien hizo una ofensiva final, en calidad de ministro del Ejército, autorizando al Ayuntamiento de Palma, en 1902, el inicio de la demolición, que se dará por completada en 1935.

En este punto hay que tener en cuenta que cuando se llega al siglo XIX y se transforma la industria, la rica burguesía, "amparada por los principios que ha heredado de la revolución francesa, consigue que el 'Poder' construya ciudades exclusivamente para ella” (Rodríguez Mas, 1964, pág. 33). Salvando las distancias, tanto en el gran París de Haussmann como en Palma crecerá el desarraigo social, y los obreros son, en parte, desplazados hacia los suburbios. Sin embargo, aunque "los ensanches se concibieron como áreas de residencia destinadas especialmente a la burguesía y las clases medias (...) esto no significa que el resultado fuera siempre ese ya que, en muchas ocasiones, sobre todo en el caso de pequeñas y medias ciudades, la burguesía prefería seguir habitando en el centro tradicional" (Capel, 1975, pág. 34). A esto mismo se refería el arquitecto Guillem Forteza Piña (18921943) cuando en 1934 escribía que "el ensanche, por falta de visión de los Ayuntamientos pasados, o por falta de energía económica de la Corporación, o, más bien creo yo, por falta de dominio técnico del problema global del urbanismo, no ha conseguido desplazar el eje de la actividad ciudadana del casco antiguo" (Forteza, 1934, pág. 11). De esta manera, el ensanche palmesano proyectado por Calvet no fue ocupado tanto por la burguesía sino por las clases populares y la gente del campo mallorquín contraria a los señores de la nobleza, pues los precios de los solares, bien estudiados por Ladaria (1992), podían resultar asequibles para las clases de menor renta. Esto permitió que estas clases, por una módica cantidad de dinero, se hiciesen propietarias de los terrenos menos inmediatos al antiguo recinto amurallado, en los que se fue alzando una arquitectura más popular, con lo cual, en cierto sentido, quedó resuelto un problema social.

Ciertamente, la burguesía pudiente y culta no se identificaba ni con la traza de calles estrechas programada por Calvet ni con la escasez de parques, y hubiese deseado que las casas del recién estrenado ensanche fuesen de más entidad, como así ocurrió en Barcelona. Sin embargo, el dinero no se invertiría tanto ahí como en ciertas reformas interiores del casco histórico de antes de la mitad de la centuria. La reforma más importante dentro de este casco fue la apertura de la avenida Jaime III en los terrenos conocidos como s'Hort d'en Moranta (unas 4,7 Ha), pues ese era prácticamente el único espacio intramuros todavía sin urbanizar (en la ortofotografía aérea del año 1956 todavía se aprecia el vacío edificatorio en este sector de la ciudad) (Figura 2). Esta avenida, junto con la urbanización general del lugar, se ejecutó en virtud de la reforma número 1 contemplada en el Plan de Reforma Interior presentado por Alomar en 1941, reforma cuyo proyecto firmaba éste mismo y el también arquitecto José Ferragut. La idea era "valorizar la extensa zona del antiguo huerto d'en Moranta, la cual, a pesar de hallarse intramuros, ha permanecido sin edificar, precisamente por carecer de un enlace directo con el centro urbano. (...) No era conveniente conservar las antiguas alineaciones, por lo que decidimos proyectar una urbanización de tipo moderno que ocupara la zona no edificada actualmente" (Alomar, 1950, pág. 50). Era allí, y no en el ensanche, donde se hallaban los verdaderos intereses económicos y la estrategia del potentado financiero mallorquín Juan March

ACE, 15 (4.5) CC BY-ND 3.0 ES | UPC Barcelona, España | Urbanismo crítico, cartografía y evolución del verde urbano en los planes de ensanche históricos de la ciudad de Palma. DOI: http://dx.doi.org/10.5821/ace.15.45.9039 
Ordinas (1880-1962). En cualquier caso, llama la atención que, en un plano topográfico militar de España del año 1914, de escala 1:100.000, correspondiente a la ciudad de Palma, aparezca ya dibujado el trazado de algunas de las líneas de las calles proyectadas por Calvet para el ensanche, cuando en realidad muchas de esas calles estaban todavía por hacer. Esto sugiere que, en los diez o quince años transcurridos después de la aprobación del plan, a los cartógrafos se les debió de acuciar para que dejaran constancia gráfica de las futuras actuaciones urbanísticas en la enorme superficie que había de acoger la urbanización extramuros.

Figura 2. Casco histórico de Palma según una ortofotografía aérea del año 1956

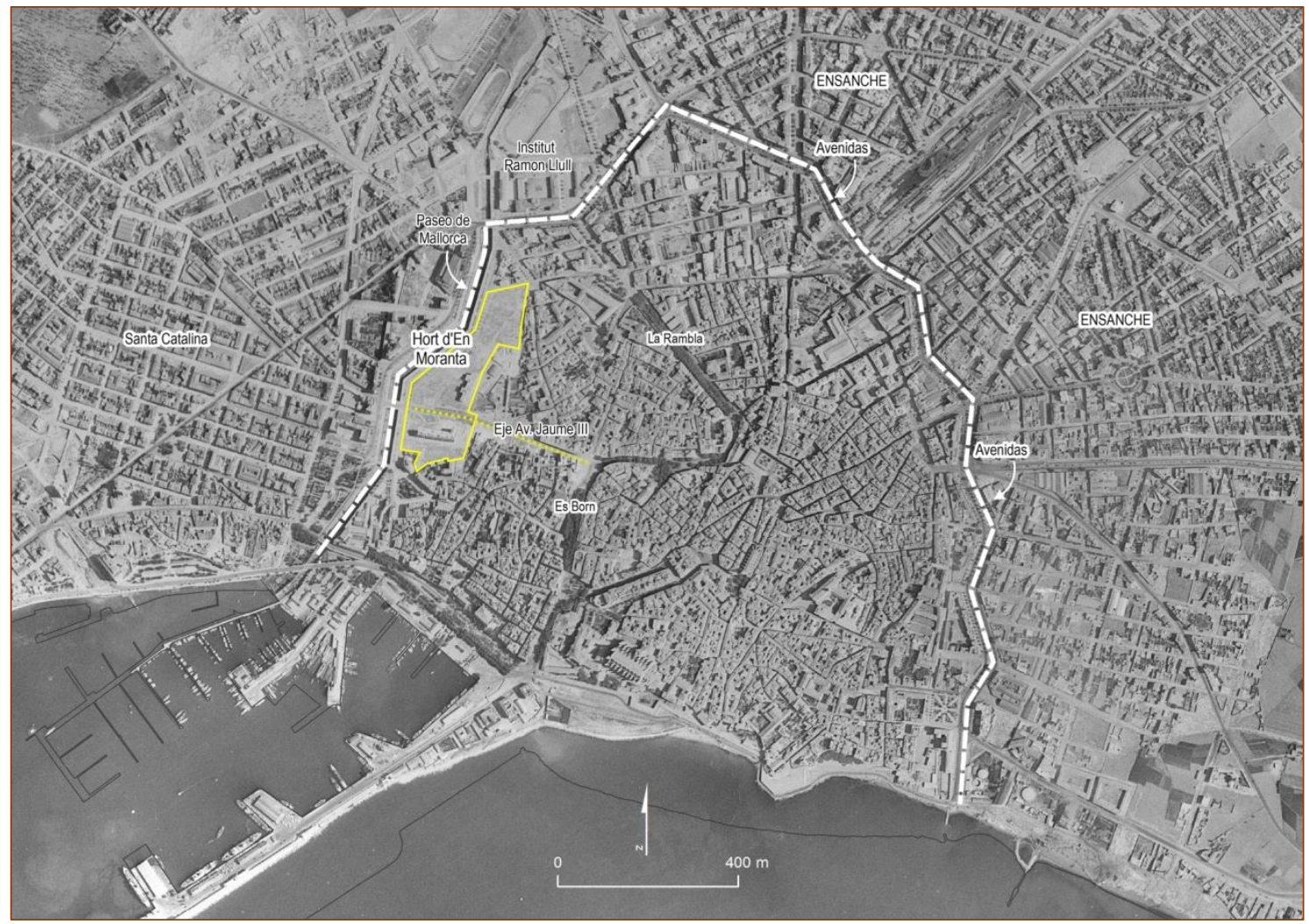

Nota: Al oeste, vacío urbano intramuros del antiguo Hort d'en Moranta todavía sin urbanizar (línea continua amarilla). En línea blanca discontinua, eje de las Avenidas y del Paseo de Mallorca sobre el trazado de las antiguas murallas. Fuente: Elaboración propia a partir de una ortofotografía del año 1956 suministrada por el Instituto Geográfico Nacional (IGN).

El plan de ensanche de Calvet fue objeto de elogios y reproches, aunque no a partes iguales, en el momento mismo en que comenzaban a hacerse visibles sus resultados. Así, el arquitecto municipal Gaspar Bennazar escribía en 1917 sobre el plan que "su práctico desarrollo nos va demostrando sus excelencias” (Bennazar, 1917, pág. 11). Sin embargo, fueron mayores los reproches, sobre todo los que dispensaba el arquitecto Forteza, cuyas críticas tenían el tinte de los nuevos tiempos racionalistas y de la influencia del arquitecto austríaco y teórico del urbanismo Camillo Sitte (1843-1903), hasta el punto de que se refería a los planes de Calvet en Palma y de Cerdà en Barcelona con las siguientes despectivas palabras: "Si del monstruoso ensanche de Barcelona se ha podido decir que era una deshonra de Europa, del nuestro, si mentalmente lo unimos con la remodelación de Roma, con el nuevo cementerio de Génova y otros engendros vecinos, podemos decir, sin miedo a equivocarnos, que es una afrenta del Mediterráneo" (Forteza, 1921, pág. 7). Críticas posteriores a las de Forteza se sucedieron con los años. En 1950, el arquitecto Alomar denunciaba la "política de abandono" a la que estaba siendo sometido el crecimiento de la ciudad extramuros, cuyo "triste resultado es este

ACE, 15 (4.5) CC BY-ND 3.0 ES | UPC Barcelona, España | Urbanismo crítico, cartografía y evolución del verde urbano en los planes de ensanche históricos de la ciudad de Palma. DOI: http://dx.doi.org/10.5821/ace.15.45.9039 
Ensanche de Palma, anodino, pobre, polvoriento, inhumano, sin carácter, sin espíritu, el más ingrato, tal vez, entre todos los ensanches de todas las ciudades del mundo" (Alomar, 1950, pág. 46). En otro lugar se refiere a él como "incomparablemente desagradable y antiestético" (Alomar, 1950, pág. 82). Más recientemente, en 1992, María Dolores Ladaria, autora de una tesis doctoral sobre el ensanche de Calvet, coincidiendo con Alomar y con Forteza, expresaba su crítica en los siguientes términos: "el ensanche de Palma resulta hoy un espacio de mejores condiciones de habitabilidad del casco antiguo, pero tampoco es un espacio agradable. Faltan lugares de esparcimiento. Se criticaba la cuadrícula defendida por Estada en su proyecto por su monotonía, y, sin embargo, el espacio creado por el plan Calvet es aburrido e impersonal” (Ladaria, 1992, pág. 90). Para esta autora, de haberse desarrollado completamente las dos zonas verdes previstas por Calvet, esto "hubiera paliado el problema de los espacios verdes".

\subsection{El 'Plan de Extensión' de Alomar (1943)}

Precisamente para intentar paliar las carencias del ensanche ejecutado según el plan de Calvet, en 1941 el arquitecto Gabriel Alomar Esteve (1910-1997) presenta, junto con un Plan General de Alineaciones y Reforma de Palma, un Plan de Extensión (Figura 1), el equivalente a un plan de ensanche. Aunque con importantes matices, se trata de la segunda corona del ensanche que hoy constituye la tercera de las piezas urbanas principales que definen la ciudad de Palma. Este plan fue definitivamente aprobado el 12 de febrero de 1943 por el Ayuntamiento de Palma, y el 23 de diciembre de 1944 por la Administración central. Transcurridos cuarenta años desde la aprobación del plan de Calvet, el espacio en el que debía desarrollarse el ensanche todavía no había sido completamente urbanizado, y faltaban por ejecutar algunas vías de circulación. Si bien Alomar respeta los fundamentos del plan pionero de Calvet, su propósito es la revisión de este incorporando al primer ensanche una segunda corona de desarrollo urbanístico, que abraza e integra legalmente buena parte de los arrabales del extrarradio. También proyecta una serie de reformas urbanísticas dentro del antiguo casco intramuros, doce en total, de las cuales se ejecutaron sólo dos, las que culminaron con la realización de la avenida Jaime III y la remodelación de la zona donde se ubicó el nuevo mercado del Olivar. Con estas dos únicas reformas quedará transformada parte de la ciudad interior ochocentista, aunque posteriormente se acabarían por ejecutar, aunque con modificaciones, la reforma de la Plaza Mayor y sus escalinatas, y los laterales del Paseo de Mallorca.

En el ensanche ya maduro al que se ha llegado en 1941, y con el objeto de aliviar el todavía congestionado casco histórico, Alomar propone una reorganización a partir de la creación de once barrios o núcleos sociales con personalidad y autonomía propia, de ahí la necesidad de dotarlos de los servicios y los espacios necesarios para tal fin. Se trataba de una organización de la ciudad basada en la idea de la "nucleización social", desarrollada por el mismo Alomar en La reforma de Palma (1950) y en Sociología urbanística (1961). Los núcleos sociales del ensanche - "barrios" o "núcleos vecinales", algunos coincidentes con las entonces demarcaciones parroquiales- eran los once siguientes: El Terreno, Son Armadans, Santa Catalina-Son Españolet, San Sebastián, Santa Catalina Thomàs, Amanecer, Hostalets, San Alonso Rodríguez, La Soledad, La Trinidad y el Molinar de Levante. Estos núcleos aparecen en el plano correspondiente de Alomar indicados no mediante polígonos con sus límites correspondientes, sino mediante unos círculos dibujados con un rotulador, lo que en la práctica resulta muy poco operativo. Sea como sea, el caso es que para cada uno de estos barrios Alomar planea el levantamiento de cuatro elementos fundamentales: una "pequeña Plaza, Paseo o espacio libre para festejos y el jardín para juego de párvulos" (Alomar, 1950, pág. 90) un comercio local, una iglesia parroquial -"con su campanario que simbolice la unidad de barrio" - y una Escuela de Primera Enseñanza.

Alomar criticará la flexibilidad que Calvet había otorgado a los límites espaciales del primer ensanche, lo que hizo que muchas zonas del extrarradio se desarrollasen sin que mediase un plan de ordenación

ACE, 15 (4.5) CC BY-ND 3.0 ES | UPC Barcelona, España | Urbanismo crítico, cartografía y evolución del verde urbano 10 en los planes de ensanche históricos de la ciudad de Palma. DOI: http://dx.doi.org/10.5821/ace.15.45.9039 
conjunto, mientras quedaban sin edificar numerosas áreas del ensanche sí planeadas. Es por esto por lo que Alomar amplía y, en parte, reorganiza el plan de Calvet, con el objetivo declarado de crear áreas terciarias de atracción que pudiesen convertirse en las citadas barriadas con personalidad propia. También introduce en la ciudad extramuros dos piezas nuevas que marcarían el desarrollo urbanístico posterior de Palma: un paseo marítimo y una vía de circunvalación separadora del espacio urbano y el rural (Figura 1). La pretensión general del plan es dar unidad y poner orden en la "forma semianárquica" en que se estaba ejecutando el ensanche de Calvet, sobre todo en los terrenos fuera del perímetro marcado para el mismo, en donde Alomar (1950, pág. 80) denuncia operaciones de "pseudo-urbanización" y de "urbanización salvaje". Para solventar el defectuoso desarrollo constructivo del ensanche, proponía una clara separación entre la zona propiamente urbana -que quedaba en el interior de una futura vía de circunvalación de la ciudad ya ensanchada- y una zona propiamente rural y "permanentemente verde" (suelo rústico o no urbanizable, en la legislación actual), en la que se prohibía la parcelación con fines residenciales.

Con la mencionada vía de circunvalación -una ancha avenida con un diseño ambiental de escaso impacto- Alomar resolvía satisfactoriamente el problema, no solventado por Calvet, del enlace de las carreteras que salían radialmente de la ciudad, y de la zona de unión entre la ciudad y el campo. Además, lograba evitar la creación de un cinturón de ronda exterior - la actual Vía de Cintura- que respondiera al típico criterio constructivo de los ingenieros de carreteras, es decir una vía diseñada como si fuese una autopista. El proyecto de la Vía de Cintura fue incorporado más tarde, en virtud de un Plan Especial de Comunicaciones del 1966, de la Dirección General de Carreteras (Ministerio de Obras Públicas). En este plan se proyectaba la Red Arterial de Palma, y con ella el proyecto definitivo de trazado de la Vía de Cintura, que es de 1968. Este anillo semicircular, que totaliza $11 \mathrm{~km}$ de largo, planteaba un primer problema urbanístico y social: cómo reducir el efecto de barrera entre las zonas habitadas situadas a ambos lados del trazado. Una ronda de circunvalación de estas características puede tener la función única de servir al tráfico rodado, pero esta función monocolor no tiene por qué resultar incompatible con la transformación de la ronda en una vía arbolada de grandes dimensiones, con puentes de comunicación entre las zonas situadas a sus lados. Esto no se hizo, y en su lugar se construyó un cinturón viario cuyo aspecto es el de la tradicional autovía.

Hay que decir que el ensanche con el que se encuentra Alomar en 1941 puede reconocerse en un plano inglés de 1943 que forma parte de los trabajos cartográficos realizados por el Inter-Services Topographical Departament (ISTD), dependiente del Inter-Services Intelligence Series (ISIS), destinados a ofrecer cobertura cartográfica urbana, suficiente y actualizada, ante una posible invasión nazi de España durante la Segunda Guerra Mundial. Los planos ingleses de un conjunto de ciudades españolas estratégicas fueron compartidos y copiados por el Army Map Service (AMS) de la U.S Army norteamericana, como es el caso del plano del Puerto de Palma, de escala 1:10.000. Éste muestra el desarrollo del ensanche de Calvet cuarenta años después de la aprobación del plan. Los dos "jardines públicos" proyectados en 1901 se rotulan como "PUBLIC GARDENS", de lo que se deduce que todavía entonces seguía viva la idea de consumar como amplias zonas verdes los márgenes de los cursos hídricos de Sa Riera y de San Magín en esos dos sectores de la ciudad.

\section{Precedentes del verde urbano antes del primer ensanche}

Fruto de las corrientes internacionales higienistas y ambientalistas del XIX, que en España había introducido el médico catalán Pere Felip Monlau Roca (es elocuente el título de su ensayo Abajo las murallas, de 1841), a finales de la centuria comienzan a verse en Palma proyectos menores de urbanizaciones en los que el verde urbano ocupa su lugar. En esta época los jardines y parques públicos venían incorporándose de forma más o menos regular al diseño de las ciudades, hasta el punto de que "la nueva ciudad del siglo XX ya no podrá concebirse sin la inclusión de espacios verdes, convertidos ya definitivamente en equipamientos sociales indispensables” (Capel, 2002, pág. 330).

ACE, 15 (4.5) CC BY-ND 3.0 ES | UPC Barcelona, España | Urbanismo crítico, cartografía y evolución del verde urbano en los planes de ensanche históricos de la ciudad de Palma. DOI: http://dx.doi.org/10.5821/ace.15.45.9039 
Antes de ello, el verde programado en Palma lo encontramos en el siglo XVIII en forma de jardines obra de particulares para sus residencias prediales o de recreo situadas en el espacio de la periferia rural, por ejemplo, en el Secar de La Real (Can Coll, 1861) o, sobre todo, en la zona de El Terreno (Ca l'Indiano, 1867). También lo encontramos en el espacio propiamente urbano, en forma de ornamentación o acompañamiento vegetal de vías urbanas y paseos públicos de herencia ilustrada, que en Palma se concretó en el camino extramuros que conducía al antiguo convento de Jesús, del que tomará su nombre el paseo arbolado de Jesús -popularmente llamado "de les Quatre Campanes"-, el primero de estas características en Palma, proyectado en 1784, y cuyo comienzo se situaba en la cabecera de La Rambla (Zaforteza, 1988). Antes de que el paseo fuese fagocitado por la urbanización del ensanche, su trazado aparecía bien dibujado en algunos planos históricos de la ciudad, entre ellos el de Lorenzo Muntaner, de 1831, con el topónimo de "Paseo de Jesús", o el plano de Antonio Togores, de 1850, con el topónimo de "Camino del Cementerio". Un segundo paseo extramuros era el camino de ronda, arbolado a ambos lados, entre el baluarte de Santa Margarita y el de San Antonio, y cuyo trazado aparece en un plano de Palma de 1851, de Francisco Coello, a escala 1:10.000.

En 1823 llegaría la primera adecuación de La Rambla como paseo arbolado, y en 1833 el proyecto del paseo urbano de Es Born (Zaforteza, 1954). Luego se crearían los jardines de la glorieta de la plaza de la Reina -primer jardín público de Mallorca, de 1863- y del Huerto del Rey en 1851. La presión constructiva consiguió que en este último se edificaran un hotel (Gran Hotel Alhambra, 1918) y un teatro (Teatro Lírico, 1902), hasta que en 1957 se recuperó como jardín de nueva planta, según un diseño del arquitecto Gabriel Alomar Esteve, autor del proyecto ganador, en 1941, del concurso para la reforma interior de Palma. A estos espacios con vegetación se sumaban ciertas plazas como la de Santa Eulàlia, de la Mercè, de l'Oli, de la Lonja o de las Drassanes, además de algunas calles con árboles como la de Unió o la de Sant Alonso -aunque aquí con un solo gran árbol-, y ciertos ámbitos frente a las antiguas puertas de entrada a la ciudad -la de Santa Catalina o la de Sant Antoni, por ejemplo-.

Es así como durante el siglo XIX la corporación municipal promueve ciertos programas y reformas urbanas de creación de espacios verdes públicos, cuya finalidad es satisfacer las demandas de recreo por parte de los distintos estratos sociales. El Ayuntamiento de Palma contaba con una comisión de arbolado, caminos y paseos, además de un grupo de trabajadores municipales dedicados a su mantenimiento. Asimismo, el verde es también obra de cementerios, que a partir del XVIII, por orden gubernativa, estarán localizados en las afueras de la ciudad, como así ocurrió en Palma, cuyo proyecto de camposanto se inauguró en 1821 en los antiguos terrenos de Son Tril·lo. Aquí dominaban árboles y arbustos odoríferos o aromáticos con el objeto de reducir el frecuente hedor, pero también árboles culturales que simbolizan la eternidad, el sosiego o la tristeza, como es el caso del ciprés o el sauce llorón.

La incorporación del verde urbano al diseño de la ciudad antes de finalizar el siglo también la vemos en un anteproyecto de urbanización, que no vio la luz, firmado en 1891 por el maestro de obras Bartolomé Ferrà, en el sector marítimo oriental de la ciudad -entre la Ronda de Levante y el caserío de El Portitxol-, sobre el cual escribe su mismo autor (Ferrà, 1891, pág. 138): “Alameda y Jardines. El terreno comprendido entre la orilla del mar y la serie de molinos (ya desmantelados en su mayor parte), lo destinamos á paseo libre del tránsito de carruajes; á jardines reservados; á parque selva; plantada de arbustos, resistentes al aire del mar, cuyo arraigo ha de ser fácil, puesto que el terreno se ha ido formando con los escombros procedentes de los derribos, y, por consiguiente, no le falta abono. En dicha selva las plazoletas y avenidas sinuosas ofrecerían sitios a propósito para el esparcimiento de la niñez, ejercitando sus fuerzas en un ambiente purificado por las brisas del mar, é impregnado de los salutíferos aromas que exhalan las plantas silvestres".

ACE, 15 (4.5) CC BY-ND 3.0 ES | UPC Barcelona, España | Urbanismo crítico, cartografía y evolución del verde urbano en los planes de ensanche históricos de la ciudad de Palma. DOI: http://dx.doi.org/10.5821/ace.15.45.9039 


\section{El verde urbano en el 'Proyecto de Ensanche' de Calvet (1901)}

El plan de ensanche de Calvet es claro en lo que se refiere a la cuestión del verde urbano, pues en la Memoria del plan se dedica un capítulo específico cuyo título reza "Jardines y arbolado". En él, el autor reconoce la utilidad de los jardines y el arbolado como "purificadores del aire", además de su función de mitigación de los rigores del clima (Calvet, 1897, pág. 77). Se trata de la típica concepción higienista y ambientalista de la matriz verde urbana promovida por los nuevos Estados liberales, pues Calvet parece que copia las ideas de Castro señaladas en el plan de ensanche de Madrid, según las cuales los espacios urbanos vacíos de edificación pueden considerarse como "extensos depósitos de aire que sirven para alimentación y renovación del de las calles que a ellos afluyen por efecto de las corrientes que se establecen" (Castro, 1860, pág. 152), mientras que el arbolado es un "un elemento tan poderoso para la higiene pública" (pág. 137). Sin embargo, en el caso de Calvet, con la excusa de que en el campo palmesano ya hay bosques que cumplen esa función, y de que la presencia del mar, por sí sola, también la cumple, su opinión es que en Palma los parques y jardines "hacen falta solamente para que sirvan de esparcimiento y recreo, para que mitiguen con la sombra los ardores del sol y para que con sus tonos simpáticos y perspectivas agradables satisfagan una necesidad artística" (Calvet, 1897, pág. 77). Esto significa que el autor del plan de 1901 confiere a sus futuros parques verdes funciones recreativas, estéticas y paisajistas, y no funciones higiénico-sanitarias, cosa de la que parece que ya se encargan los bosques periurbanos y el mar.

Figura 3. Palma: Distribución de los principales espacios verdes planeados por Calvet (1901), Bennazar (1917) y Alomar (1943)

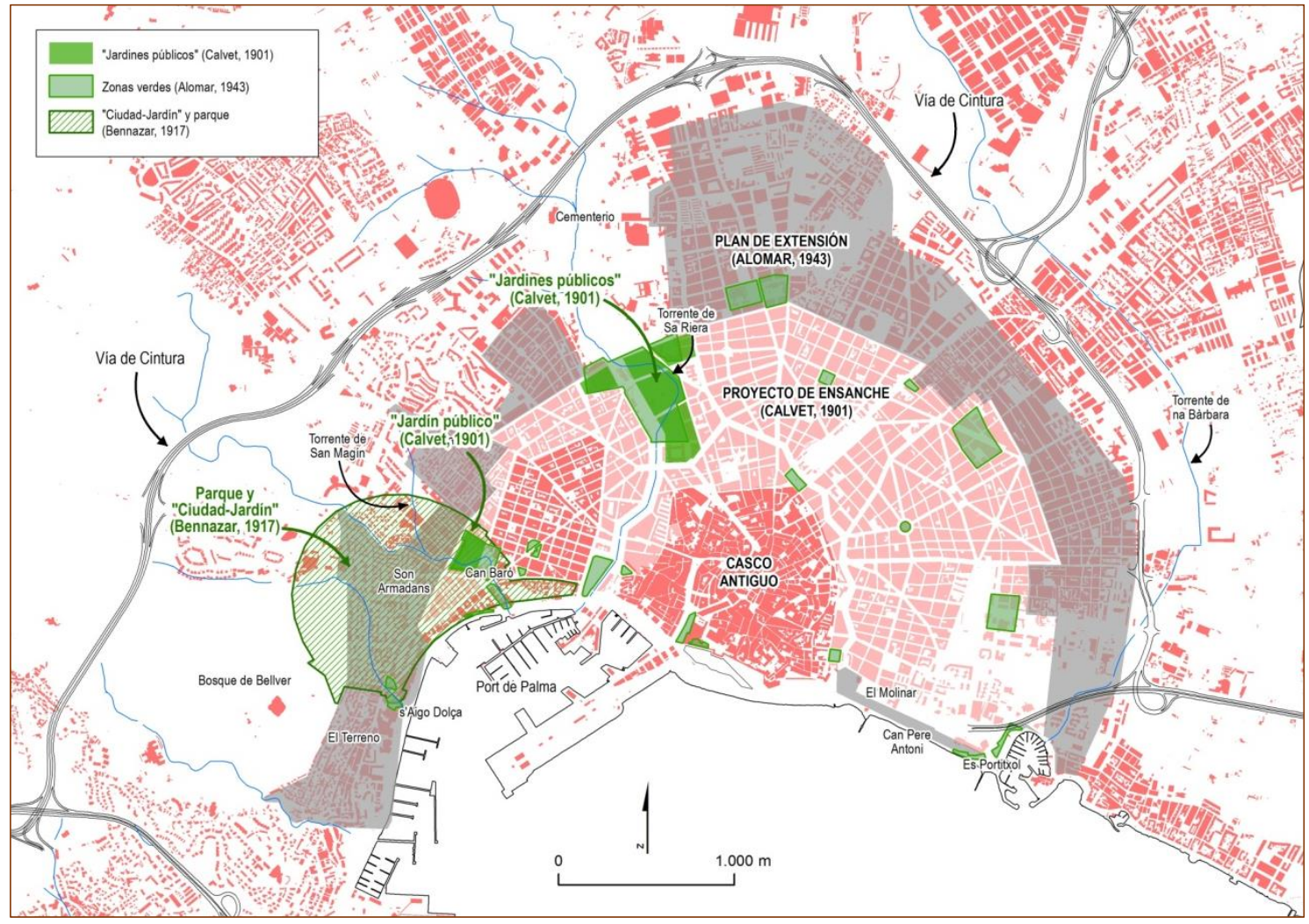

Fuente: Elaboración propia a partir de la base cartográfica del Mapa Topográfico de las Islas Baleares de 2006, de escala 1:5.000.

ACE, 15 (45) CC BY-ND 3.0 ES | UPC Barcelona, España | Urbanismo crítico, cartografía y evolución del verde urbano en los planes de ensanche históricos de la ciudad de Palma. DOI: http://dx.doi.org/10.5821/ace.15.45.9039 
Los terrenos en los que Calvet emplazará sus “jardines públicos” (Figura 3) serán aquellos considerados espacios insalubres, con excesiva pendiente o, simplemente, los que suponían un peligro para la edificación. El primer gran jardín (Figura 4a), seccionado en cinco grandes cuadrados que totalizan una superficie de 16,9 Ha, lo sitúa al noroeste, anexado a la ciudad intramuros, en la zona que bordea los márgenes del curso hídrico de Sa Riera y colindante con el antiguo "Paseo de Jesús". La situación de este gran parque quedaba justificada por la pronta presencia de agua en el subsuelo, y porque la presencia del cementerio en sus proximidades descartaba la posibilidad de edificar en la zona. El segundo "jardín público", con una extensión de 3,1 Ha, Calvet lo situará más periféricamente al oeste de la ciudad, detrás del arrabal de Santa Catalina. También coincide con un cauce de agua, en este caso el torrent de San Magín a su paso por Can Baró, y se sitúa sobre unos terrenos accidentados, por lo que también quedaban descartados para la edificación, pero no para su adecuación como parque.

Figura 4. Detalle de parques y jardines públicos proyectados en los planes de ensanche históricos de Palma

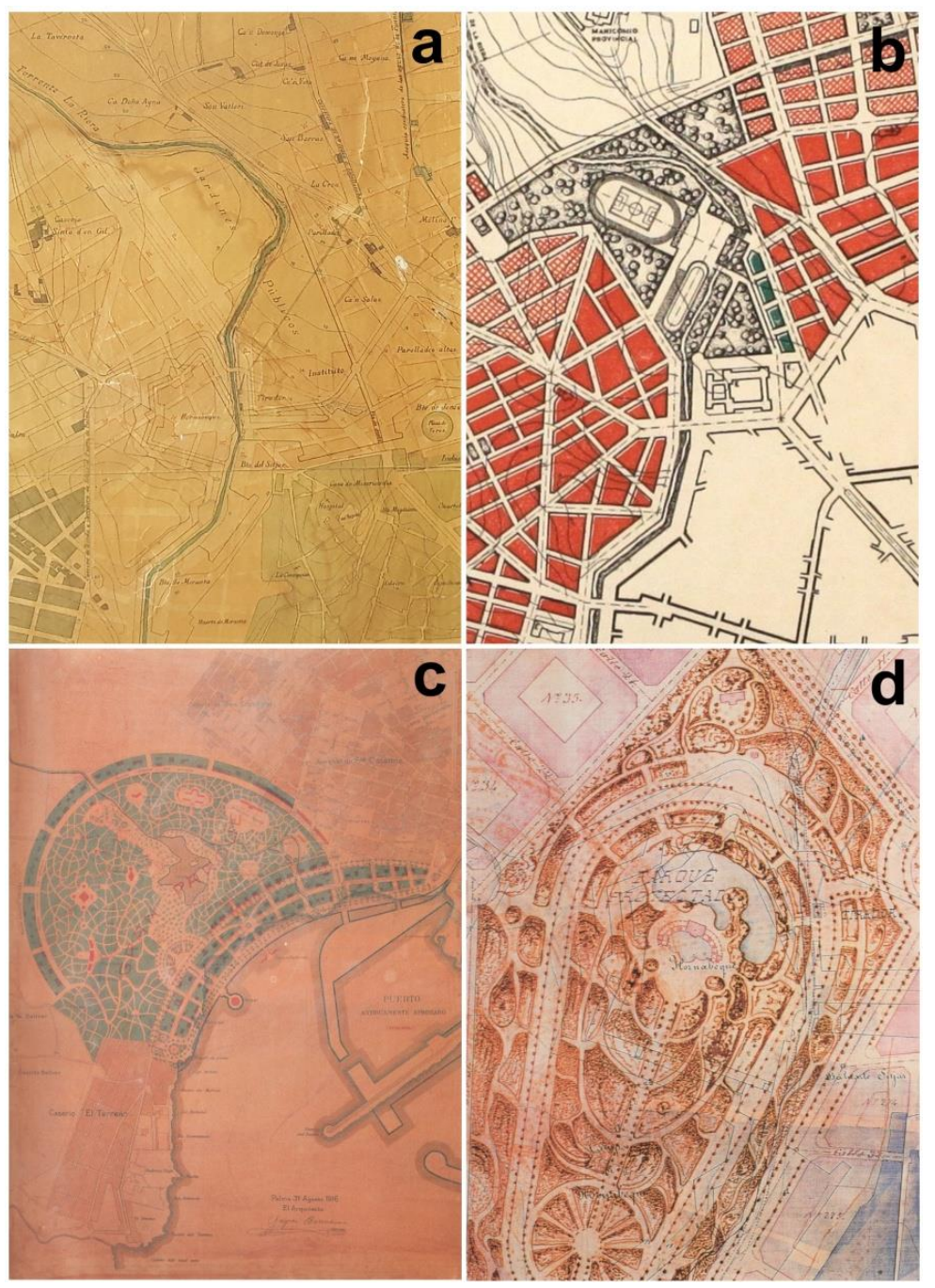

Nota: (a) Propuesta de Calvet (1901) de "Jardines públicos" en los márgenes del torrent de Sa Riera; (b) Propuesta de Alomar (1943) para estos mismos jardines; (c) "Gran Parque" proyectado por Bennazar en 1917 (no realizado); (d) "Parque Proyectado" al noroeste de la ciudad extramuros, según el plan de ensanche perdedor de García Faria (1897). Fuente: Imagen fotográfica de detalle de los planos originales de los planes de ensanche históricos consultados.

ACE, 15 (4.5) CC BY-ND 3.0 ES | UPC Barcelona, España | Urbanismo crítico, cartografía y evolución del verde urbano 14 en los planes de ensanche históricos de la ciudad de Palma. DOI: http://dx.doi.org/10.5821/ace.15.45.9039 
Al confrontar el desarrollo del ensanche con los planos cronológicamente más próximos a la fecha del teórico comienzo de las obras de urbanización -1902-, se advierten algunos aspectos de interés, como por ejemplo que las dos grandes zonas verdes planeadas, como el ensanche entero, aparecen muy bien representadas en un plano de Palma a escala 1:8.000, entregado para la obra España Regional por el entonces secretario del Ayuntamiento Benito Pons Fàbregues y fechado en ca. 1920 (Tous, 2009). Aunque en esta fecha la urbanización del ensanche no se había completado, su representación cartográfica da una idea clara de la desigual distribución de las zonas verdes programadas por Calvet, pues toda la mitad oriental del ensanche carece de este tipo de espacios. En el plano de Benito Pons los "jardines públicos" programados al noroeste y al oeste de la ciudad aparecen muy bien indicados, delimitados y simbolizados como tales, cosa que pone de manifiesto la voluntad del Ayuntamiento palmesano de consumar el plan de Calvet, veinte años después de su aprobación. Otra muestra es el dibujo del trazado viario junto a los futuros "jardines públicos" del noroeste, trazado que debía albergar el desvío del torrent de Sa Riera, anulándose el meandro existente, y cuyo diseño final se correspondía con el que adopta el Paseo de Mallorca actual.

Por otra parte, el plan de Calvet establecía la creación de tres grandes paseos: uno que aprovechaba el cauce urbano de San Magín, otro litoral al este de la ciudad, junto a la playa de Can Pere Antoni y El Molinar - la explanada de Can Pere Antoni se dedicaba a jardín e hipódromo (Seguí, 1985-87)-, y un tercero con la denominación de "gran paseo de ronda" - las actuales Avenidas-, que circunvalase el antiguo recinto amurallado entre el mar y el antiguo Hornabeque, y que completaba una longitud de $2.461 \mathrm{~m}$. Este "gran paseo" tendría el aspecto de un boulevard, es decir, tal y como lo define el Diccionario de la Real Academia Española, un paseo central arbolado de una avenida o calle ancha. Con el tiempo, el previsto paseo de ronda ha devenido en una gran vía circulatoria: las actuales Avenidas, cuyo trazado reproduce el de las antiguas murallas.

En cualquier caso, en los tres paseos citados el arbolado tenía cabida, sobre todo en el caso del paseo litoral. Si Calvet valora como suficiente la matriz verde que envuelve externamente la ciudad, y la hace penetrar tímidamente en su interior con la creación de dos reservas verdes en forma de sendos “jardines públicos", también planea la plantación de árboles, aunque con ciertas restricciones. El objetivo es plantarlos en "todas las calles que lo consientan, y lo permiten todas las plazas, paseos y calles de 1ํ y 2o orden cuyas anchuras varían desde sesenta metros a veinte” (Calvet, 1897, pág. 78), todo lo cual totaliza 48,0 km de calles y paseos arbolados. Ello no es óbice para que Calvet haga ciertas sugerencias según las cuales la cuestión del arbolado viario no requiere mayores atenciones que las indicadas, por cuanto que "la cuestión del arbolado es una obra accesoria cuya necesidad varía con el desarrollo de la población” (Calvet, 1897, pág. 78), de manera que no cabe entrar en "pormenores y pequeñeces".

Visto así, Calvet considera que el diseño de la ciudad no debe preocuparse por la planificación exhaustiva de los espacios con vegetación, ni tampoco por la aplicación de modelos reglados de distribución de estos, pues, según el autor, pueden suponer "si llegaran a aprobarse, trabas para lo futuro". Tanto es así que en las calles de tercer orden -las de diez metros de ancho- no hay que consentir la plantación de árboles "porque perjudicarán grandemente a las casas y al tráfico". Ya que aproximadamente un $70 \%$ de las calles proyectadas por el plan de 1901 eran calles de diez metros, y las de treinta metros eran sólo tres (31 de diciembre, Aragón y carretera de Manacor), resulta patente el desinterés de Calvet por el arbolado viario en buena parte de la futura ciudad ensanchada.

Durante las primeras décadas del siglo XX la jardinería pública en el ensanche avanzó muy lentamente, aunque se acometieran obras de remodelación de ciertas plazas, como la de García Orell - popularmente conocida como plaza de las Columnas-, según un proyecto del arquitecto Forteza, de 1933, ideando para ello una rotonda circular rodeada de columnas, con un jardín interior. El mismo Forteza había proyectado en 1921 un parque en el antiguo glacis militar de Sa Faixina, junto al arrabal de Santa Catalina. Aunque este proyecto no se llevó a cabo, inspiró la realización del parque actual,

ACE, 15 (4.5) CC BY-ND 3.0 ES | UPC Barcelona, España | Urbanismo crítico, cartografía y evolución del verde urbano en los planes de ensanche históricos de la ciudad de Palma. DOI: http://dx.doi.org/10.5821/ace.15.45.9039 
donde en el año 1935 ya se había construido el llamado Grupo Escolar Jaime I. Con la transformación del glacis en zona verde al parecer se cumplieron los designios -o premonición- de Forteza, para quien "también esta gran explanada que mira al mar debería ser objeto de una adecuada urbanización. Un pinar tupido que la cubriese de sombra; el elegante motivo de las cuatro campanas que ornamentase uno de los cruces de avenidas o paseos; en el punto más alto un edificio para escuelas municipales; entre el jardín otro edificio menor para Biblioteca popular; todo enriquecido por la proximidad del grácil Puente de la Riera" (Forteza, 1921, pág. 45).

Prueba de la tardanza con que el verde urbano parece que llegó al dominio extramuros, y del afán exclusivamente residencial de los primeros propietarios, es la mención crítica que a propósito de esto hacía el mismo Forteza en 1931: "Aparte del Instituto [Ramon Llull, construido en 1914], tan mal emplazado con relación al eje de La Rambla, no se ha levantado en el ensanche ningún edificio público: ni una tenencia de alcaldía, ni una iglesia, ni una escuela primaria, ni unas termas, ni una clínica de urgencia, ni una biblioteca popular, ni un mercado, ni una estafeta de correos, y casi se puede decir que no se ha plantado un árbol, ni se ha hecho brotar del suelo una flor" (Sureda y Alomar, 1946, pág. 162). En otro librito crítico, Urbanisme mínim (1934), Forteza abogaba por "aprovechar de inmediato las canalizaciones de agua que emprendió con obligada preferencia el Ayuntamiento, con el objeto de impulsar y prodigar la vegetación en masa, en jardines y parques, así como llevar a cabo el máximo posible de plantaciones de arbolado, tanto en las vías y plazas como en el interior de las manzanas" (Forteza, 1934, pág. 25). Este arquitecto destacará la figura del jardín como epítome de la ciudad ornamentada, y en relación con él abogará por aprovechar "nuestro parentesco arquitectónico con Italia", lo que significa "no dejar sembrar a las sociedades protectoras de las plantas un ejemplar de cada especie botánica porque sí, pues la jardinería no está exenta de poder caer en el ridículo" (Forteza, 1921, pág. 33). Los ejemplos modélicos de los jardines filosofales de Grecia, los de las villas romanas, los de la dominación árabe, los de los palacios Borghesse, Aldobrandini o Isola-Bella, o los de Forestier en la colina barcelonesa de Montjuïc, son suficientes para abandonar la idea de determinadas actuaciones que no pertenecen a la larga tradición mediterránea o europea en materia de jardines.

Por otra parte, cuando se revisan las Memorias de Secretaría del Ayuntamiento de Palma redactadas en la época en que se está ejecutando el ensanche de Calvet, se observan algunos aspectos de interés. El primero, el hecho de que en las memorias posteriores a la fecha de inicio de las obras de urbanización aparece un capítulo que reza "Negociado de Ensanche y Murallas", y dentro de él un apartado con el nombre "Arbolado público", o simplemente "Arbolado". A partir de la Memoria del año 1938, en el capítulo "Obras varias" o el de "Negociado de Obras y Reforma Interior", hay un apartado que reza "Arbolado y jardines". El segundo aspecto de interés recae en las especies arbóreas utilizadas con más frecuencia en las calles y vías del ensanche palmesano todavía en construcción, que son los plátanos (Platanus hispanica) y las acacias (probablemente Robinia pseudoacacia L.), sin menoscabo de otras especies tales como los pinos (Pinus halepensis), las sóforas (Sophora japonica L.) o las truanas (Ligustrum lucidum Thunb.). La elección de estas especies no debía de ser arbitraria, pues se trata de árboles de crecimiento rápido y en general tolerantes al calor, a la sequía y a la proximidad al mar, es decir las condiciones climáticas prototípicas de una ciudad como Palma. Así, en la Memoria de Secretaría del ejercicio del año 1929 se lee: "Arbolado Público. Después de cubrir las faltas que en el arbolado del Ensanche se habían producido, se procedió a la plantación de 120 pies, en su mayoría plateros y los restantes, acacias. Con motivo de la construcción del Gran Coliseo Balear, se efectuó la plantación de plateros en la porción de Ronda exterior con la cual linda la nueva Plaza de Toros" (pág. 36). En la Memoria de Secretaría del ejercicio del año 1932 se lee: "Arbolado. Con el fin de fomentar el arbolado público, va aumentando de una manera progresiva la plantación de árboles en el Ensanche, en todas aquellas vías de veinte o más metros de anchura. En el ejercicio de referencia se han plantado plateros, sóforas, pinos, acacias, bolas y truanas" (pág. 51). A partir del año 1951 las Memorias de Secretaría prescinden del capítulo "Negociado de Ensanche y Murallas", y el apartado de "Arbolado y jardines" aparece ahora en un nuevo capítulo titulado "Urbanismo". También

ACE, 15 (4.5) CC BY-ND 3.0 ES | UPC Barcelona, España | Urbanismo crítico, cartografía y evolución del verde urbano 16 en los planes de ensanche históricos de la ciudad de Palma. DOI: http://dx.doi.org/10.5821/ace.15.45.9039 
aparece un capítulo titulado "Ensanche" o bien "Zona de Ensanche", en el que por primera vez aparece un apartado con el nombre "Parques y jardines: espacios verdes", lo que indica la normalización del uso social que a mediados del siglo comenzaban a tener expresiones como 'zona verde' o 'espacios verdes'.

\section{El verde urbano en el 'Plan de Reforma' de Bennazar (1917)}

En el año 1916 el arquitecto Gaspar Bennazar presenta por encargo del Ayuntamiento un Plan General de Reforma de Palma (Figura 1), que por lo visto fue "aprobado por la Superioridad en 27 de diciembre de 1917" (Seguí, 1981, pág. 477), aunque nunca se llegó a ejecutar. El plan ha sido considerado un plan imaginativo, pero ilusorio y utópico, lo que en la práctica lo hizo inviable. Según Seguí (1981, pág. 489), "su realización hubiera supuesto una profunda alteración del núcleo antiguo, sin respetar zonas de importancia histórica o bien edificios de valor artístico y monumental”. La intención del plan era abordar la reforma urbanística del antiguo casco intramuros, tarea soslayada por Calvet, y, en cuanto al ensanche, prolongarlo hasta el mar, pero sin modificar su estructura general. Unos años antes, Bennazar, profesionalmente muy activo, había participado en la ordenación urbanística de la actual plaza de España (1905) y en la realización del Paseo de Sagrera (1910), en un solar junto al muelle de Palma, frente a la Lonja medieval, enajenado después del derribo de un sector marítimo de la muralla. El paseo fue convenientemente arbolado con palmeras y posteriormente ajardinado junto al Consulado de Mar, sede actual del Gobierno de las Islas Baleares. En calidad de arquitecto municipal, Bennazar dirigió durante más de treinta años las obras de trazado del ensanche de Calvet, en cuyas plazas no consideró necesario el ajardinamiento, opinión que fue muy atacada por Forteza (1931) y por Alomar (1950).

Si la reforma urbanística de Bennazar respetaba íntegramente los "jardines públicos" programados por Calvet al noroeste de la ciudad, su gran y principal proyecto era la creación, al oeste de la ciudad, de una ciudad-jardín entre el arrabal de Santa Catalina y s'Aigo Dolça, una gran urbanización ajardinada de hoteles y chalets (Figura 3). Junto a ella, en Son Armadans, también proyectó un enorme "Gran Parque" (Figura 4c) en donde ubicaba un conjunto de edificios públicos rodeando un lago. A estas urbanizaciones se accedía mediante tres anchas vías desde el Paseo de Sagrera, es decir en lo que hoy es el Paseo Marítimo. En el lado opuesto, al este del municipio, Bennazar proyectó un balneario en la Pared Blanca, a medio camino entre el caserío marítimo de El Portitxol y Cala Gamba, también bajo los preceptos teóricos de una ciudad-jardín. Actuaciones como estas iban dirigidas en gran parte a la burguesía, que venía reclamando parques más o menos selectos y urbanizaciones ajardinadas para su esparcimiento y jactancia.

Más tarde, en 1921, la sociedad Progreso Urbano S.A. aprobó la creación de una "estación veraniega" o urbanización costera de carácter turístico y residencial, con el nombre "impropio", según Díez Monge (1988), de Ciudad Jardín, pues la idea resultó tan solo una "tentativa fracasada". El autor del proyecto es desconocido, aunque se ha supuesto al arquitecto Jaime Aleñá Guinart (1870-1945), autor de un Anteproyecto de Reforma de Palma presentado en 1912, cuyo ámbito de actuación era sólo el del casco urbano intramuros (Aleñá, 1916; Seguí, 1990). Sobre el proyecto de la Pared Blanca, el arquitecto Forteza, habiendo propugnado en 1930 la necesidad de utilizar la zonificación en los planes de ensanche (es decir, separar y delimitar en Palma una zona de negocios, la zona de viviendas con una subzona de lujo y otra de viviendas baratas, y zonas industriales y de comercio), escribía que las viviendas de lujo debían ubicarse preferentemente en las áreas periféricas de la ciudad. Para ello proponía los emplazamientos de Es Jonquet, s’Aigo Dolça y Son Armadans, en los que la norma debía ser "dar mucha extensión a los jardines a expensas de la amplitud de las calles" (Sureda y Alomar, 1946, pág. 164). En cuanto a las subzonas de viviendas menos pudientes, señalaba que éstas podían construirse también siguiendo los preceptos de la ciudad-jardín, "pues las barriadas más modestas se urbanizan con los mismos sistemas y orientación que las barriadas de lujo. Entramos de lleno en

ACE, 15 (45) CC BY-ND 3.0 ES | UPC Barcelona, España | Urbanismo crítico, cartografía y evolución del verde urbano 17 en los planes de ensanche históricos de la ciudad de Palma. DOI: http://dx.doi.org/10.5821/ace.15.45.9039 
el imperio de la Ciudad-jardín, que se considera hoy como un intermedio entre la ciudad actual y la ciudad futura" (Sureda y Alomar, 1946, pág. 164).

\section{El verde urbano en el ‘Plan de Extensión’ de Alomar (1943)}

En relación con el verde urbano, además de su consabida función ambiental, higiénica y estética, Alomar (1961) considera que tiene una función social. El arquitecto denuncia el déficit de zonas verdes y espacios libres en el interior del ensanche de Calvet, sobre todo en su mitad oriental, lo que a la larga ocasionará su sobredensificación edificatoria. Por eso advierte de la necesidad de ampliar a un tercer parque urbano los dos ya proyectados por Calvet en el noroeste de la ciudad (en los márgenes del torrent de Sa Riera) y en el oeste (en los márgenes del torrent de San Magín), parque que situará también al oeste, en s'Aigo Dolça. En general, propone la creación de un conjunto de espacios ajardinados rodeando radialmente la ciudad (Figura 3), gran parte de los cuales ubica en la primera corona del ensanche. Estos parques debían formar parte sustancial de cada barrio o "núcleo vecinal", desde Santa Catalina-Son Españolet (parque del torrent de San Magín) hasta el Molinar de Levante, pasando por el de San Sebastián, El Amanecer, Hostalets, La Soledad y Santa Catalina Thomàs (parque del torrent de Sa Riera). Algunas de estos espacios verdes incluían formalmente campos para el deporte, merenderos y kindergarten o "jardines de infancia”, expresión creada por el pedagogo Friedrich Fröbel (1902) para referirse a las escuelas para niños y niñas en las que se habilita una zona de huerto o jardín con parcelas de tierra en las que los niños aprenden a cultivar plantas. Por su parte, las zonas que Alomar calificaba como de "edificación extensa", que parecen pensadas para resolver los problemas producidos por el crecimiento urbano desmedido, estaban destinadas a residencias unifamiliares y plurifamiliares siempre rodeadas por un jardín. Por su primitivo emplazamiento geográfico dentro de un medio muy cercano al mundo rural, estas zonas de edificación extensiva se localizaban en núcleos periféricos como El Amanecer, Son Armadans, El Terreno o el Molinar de Levante.

En el caso de los “jardines públicos” planeados por Calvet al noroeste, Alomar redibuja allí cuatro manzanas de edificios (Figura 4b), manzanas que no estaban previstas en el plano del primer ensanche, y cuya ejecución acabará restando superficie verde al lugar, aunque Alomar trató de desagraviar esta circunstancia con una calificación para esos edificios de "zona de edificación extensa”, es decir rodeadas de jardín. Para compensar esa merma, el Ayuntamiento de Palma, en el Plan General de Ordenación Urbana de 1985, destinó a jardines públicos ciertos espacios libres de la ciudad que de otra forma debían haberse ocupado por edificios, como por ejemplo el antiguo glacis militar de Sa Faixina, aunque en el plan de Alomar ya se había previsto su ajardinamiento.

\section{El verde urbano heredado en los Planes Generales de 1964, 1973, 1985 y 1998}

A partir de los años 60 del siglo pasado los planes municipales de ordenación urbana, apoyados en los planes de Calvet y Alomar, no pueden impedir el creciente desorden urbanístico, que venía acompañado por un aumento rápido y exagerado de la población a causa de la atracción creada por la creciente actividad turística. Comenzaba así una presión inmobiliaria que la estructura urbana vigente no podía absorber, de tal modo que la Oficina Técnica del Ayuntamiento de Palma redactó él mismo, en 1964, un Plan General de Ordenación Urbana, el primero después de la entrada en vigor en España de la Ley sobre Régimen del Suelo y Ordenación Urbana, en 1956. Hasta este año, el Ayuntamiento de Palma tuvo pocos medios legales con los que controlar sus desarrollos urbanos (Cabellos, 2016), entre ellos unas Ordenanzas Municipales del año 1915 -aunque entraron en vigor en 1917-, mediante las cuales se regulaban de forma decisiva ciertos aspectos urbanísticos tales como

ACE, 15 (4.5) CC BY-ND 3.0 ES I UPC Barcelona, España | Urbanismo crítico, cartografía y evolución del verde urbano 18 en los planes de ensanche históricos de la ciudad de Palma. DOI: http://dx.doi.org/10.5821/ace.15.45.9039 
las alineaciones de las calles y la altura de las edificaciones. En un Estado decimonónico liberal como el español, muy centralizado y de estructura napoleónica, apenas estaba desarrollada la legislación urbanística, de manera que cuando se promulgó la citada Ley del Suelo, el instrumento de referencia pasó a ser el Plan Director Territorial o el Plan General de Ordenación Urbana. En 1976 se aprueba una segunda Ley sobre Régimen del Suelo y Ordenación Urbana (Matesanz, 2009), técnicamente de buena calidad y con un buen reglamento de gestión y de planeamiento, recalcando el papel de las autoridades urbanísticas en la planificación.

El objeto del Plan General de Palma de 1964 era dar solución a las urgentes necesidades de residencia surgidas del aumento de la población, por lo que el resultado final fue un plan desarrollista que incrementó sustancialmente las alturas permitidas de la edificación, lo que supuso una sobredensificación edificatoria en el ensanche. En realidad, se trataba de un plan cuyo fin era operar como agente de legalización de las expectativas urbanísticas del momento. La solución a los problemas de residencia también pasó por la eliminación de ciertas zonas que en los planes anteriores habían sido calificadas como zonas verdes, además de favorecer la edificación en suelo rústico utilizando las parcelaciones destinadas sólo a uso agrícola de regadío (2.000 $\mathrm{m}^{2}$ ) y de secano (15.000 $\left.\mathrm{m}^{2}\right)$, y otorgando el derecho generalizado a disponer de $1 \mathrm{~m}^{3}$ por cada $5 \mathrm{~m}^{2}$ de superficie, mientras no existiese el peligro de formación de un núcleo de población. En la práctica, la edificación inicialmente aislada en suelo rústico fomentó la aparición en la periferia de arrabales urbanos sin equipamiento y con graves deficiencias de diseño.

En virtud del Plan General de 1964, el teórico segundo parque de Palma en importancia -el "jardín público" en Can Baró, previsto en 1901 por el plan de Calvet, y que el plan de Alomar de 1943 respetaba-, fue completamente artificializado bien por la presencia de edificios con función residencial, bien por la presencia de instalaciones deportivas -el Mallorca Tennis Club, hoy declarado Bien de Interés Cultural, obra racionalista del arquitecto catalán Francesc Mitjans-. El desarrollo urbanístico en este sector de la ciudad enmascaró casi por completo la traza del torrent de San Magín hasta su desembocadura en el vigente Paseo Marítimo, un cinturón viario litoral cuyo trazado final se materializó entre los años 1949 y 1962, momento en que adquiere sus dos calzadas y ancho actuales. En virtud de la revisión del vigente Plan General de Ordenación Urbana, de 1998, esta vía de circulación litoral está en vías de remodelación y transformación parcial en boulevard.

Como respuesta a las desproporciones ocasionadas por el desarrollo del Plan General de 1964, se propuso una revisión de este, que fue encargada al arquitecto y catedrático Manuel Ribas Piera. Esta revisión, aprobada el 21 de mayo de 1973, se propone reforzar la zonificación en el conjunto del segundo ensanche, y dotar a Palma de grandes zonas de equipamientos, tan grandes y, en cierto sentido, utópicas que no llegaron a ejecutarse, sobre todo porque no iba a favor de los intereses económicos de los promotores, aunque la Crisis del Petróleo tampoco favoreció su despliegue. En relación con el verde urbano, en la Memoria de Secretaría del Ayuntamiento de Palma del año 1973 puede leerse: "Para solventar el problema grave de la falta de zonas verdes existentes en esta Ciudad y con ello dar cumplimiento a la política municipal de dotar de zonas verdes la Ciudad, fueron adquiridas las siguientes parcelas, ambas situadas en la zona del Plan de la Playa de Palma" (pág. 68). Se constata así un creciente interés de la corporación municipal por la matriz verde urbana, interés que recogerá el Plan General de Ribas Piera, quien en su presentación (1973, pág. 49) propugnará para Palma "un sistema de espacios verdes -tan urgente en Palma- y el necesario equipo comercial y escolar; todo ello, propuesto en términos de gran generosidad de espacios, aunque paradójicamente invisible en los planos". Con esto, Ribas Piera denunciaba la infradotación y devaluación a que había llegado el ensanche palmesano, principalmente su sector oriental.

Algunos años después, en 1985, bajo la dirección del arquitecto Manuel Cabellos, un equipo técnico del Ayuntamiento de Palma redactó una revisión del plan vigente de Ribas Piera, revisión en la que, por primera vez, se proponía revertir el crecimiento de la ciudad. Para ello se emprendió un plan de

ACE, 15 (4.5) CC BY-ND 3.0 ES | UPC Barcelona, España | Urbanismo crítico, cartografía y evolución del verde urbano 19 en los planes de ensanche históricos de la ciudad de Palma. DOI: http://dx.doi.org/10.5821/ace.15.45.9039 
movilidad y el acomodo de las ordenanzas de edificación y las densidades a la protección del carácter de las barriadas de Palma (Cabellos, 2016). También se emprendió un plan de dotación de equipamientos y servicios mejor y más homogéneamente distribuidos, además de procurar la rehabilitación de ciertas áreas degradadas del antiguo casco urbano mediante la realización de Planes Especiales de Reforma Interior (PERIs). Estos se aplicaron con éxito en barriadas como la del Puig de Sant Pere, Sa Calatrava o Sa Gerreria. La dotación de equipamientos del Plan de 1985 incluía de forma primordial los espacios verdes, principalmente en las zonas relegadas de la periferia. Este Plan y el posterior de 1998 centraron la atención en la protección del suelo no urbanizable, sujeto a las presiones derivadas de la congestión edificatoria del ya gran ensanche palmesano, a la que se intentó dar solución ocupando los terrenos urbanos todavía vacíos. En la década de los noventa la presión también era poblacional, lo que acabó produciendo, una vez entrado el nuevo siglo, unas cifras de densidad poblacional altas no sólo en ciertas áreas del ensanche, sino también en las barriadas de la periferia y en la fachada marítima.

Figura 5. Palma: Distribución de los espacios libres y zonas verdes recogidos sucesivamente en los Planes Generales de Ordenación Urbana de 1973, 1985 y 1998

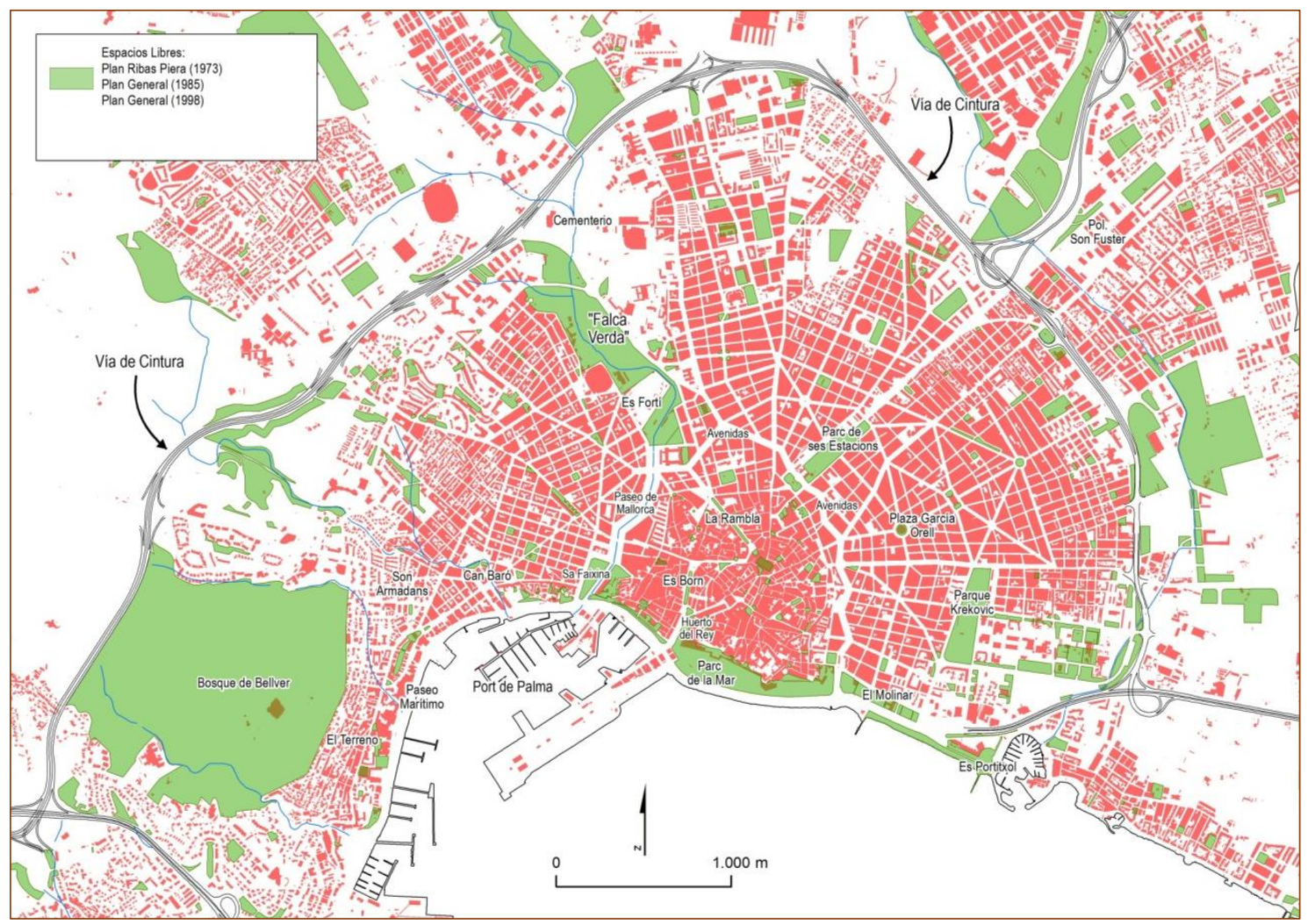

Fuente: Elaboración propia a partir de la base cartográfica del Mapa Topográfico de las Islas Baleares de 2006, de escala 1:5.000.

En lo que se refiere a los espacios libres (Figura 5), el Plan General de 1985 promueve la creación de un gran parque público urbano - la Cuña Verde de Sa Riera o Falca Verda, en catalán-, cuyo origen genético y urbanístico se encuentra precisamente en los "jardines públicos" planeados por Calvet en 1901. El Plan de 1985 califica esa futura Cuña Verde como Área de Régimen Singular, que incorpora como espacios libres públicos los terrenos del club militar de Es Fortí y los del antiguo estadio Lluís Sitjar. Ambas infraestructuras serían excluidas del gran parque por el Plan General de Ordenación Urbana siguiente, de 1998, que reformula algunas de las actuaciones previstas por el Plan precedente. Esta reformulación consiste en una distribución de la superficie del Sistema General de Espacios

ACE, 15 (4.5) CC BY-ND 3.0 ES | UPC Barcelona, España | Urbanismo crítico, cartografía y evolución del verde urbano 20 en los planes de ensanche históricos de la ciudad de Palma. DOI: http://dx.doi.org/10.5821/ace.15.45.9039 
Libres Públicos de la Falca Verda entre diferentes sectores de suelo urbanizable programado, hasta ocupar una superficie de suelo de 26,4 Ha, obtenido por compensación. Esta superficie supera ciertamente las 16,1 Ha de los "jardines públicos" previstos en el plan de Calvet para esta zona de la ciudad, pero la Falca Verda sólo en parte puede atribuirse la categoría de un verdadero "jardín". Además, su teórica unidad geométrica viene quebrada por la presencia de diversas construcciones colindantes con el parque o dentro de él (el antiguo velódromo del Tirador y el antiguo canódromo Balear), además de un viaducto -el del torrent de Sa Riera-. También quiebra la unidad del parque el solar del antiguo estadio Lluís Sitjar y, sobre todo, la obstrucción que supone el ya citado complejo del club militar de Es Fortí, de carácter privado, que fue urbanizado sobre el cuadro central de los jardines públicos previstos por el plan de Calvet, y que hoy ocupa una superficie de 4,6 Ha.

\section{Discusión y conclusiones}

A partir del examen detallado de la presencia del verde urbano en los tres planes de ensanche y de reforma aprobados para la ciudad de Palma -aunque sólo el primero llegó a ejecutarse en su mayor parte-, se ha corroborado que en todos ellos se advierte el peso específico de los espacios verdes y de esparcimiento público, destinando a este fin ciertos sectores de la ciudad, aunque con distintos resultados finales. Cuando se acomete un examen comparativo entre lo planificado en el pasado y sus resultados en el presente, el traslado de lo planeado a la realidad permite establecer no sólo el grado de cumplimiento e incumplimiento y la fidelidad al plan urbanístico primigenio, sino también la capacidad de previsión del planificador y la voluntad de actuación por parte de las corporaciones municipales.

En lo que se refiere a las posibilidades de los equipamientos verdes en las calles, plazas y parques públicos de Palma programados en 1901, su déficit en los primeros años de construcción del ensanche fue denunciado, al menos, por dos arquitectos y teóricos del urbanismo de gran influencia, como fueron Forteza y Alomar. Éstos intentaron subsanar esa carencia proponiendo ciertas reformas urbanísticas que favorecían la presencia de espacios bien vegetados, además de procurar su ajardinamiento con fines estéticos. Bennazar, aunque quimérico, también trató la matriz verde urbana, pero respecto a ella sólo hizo generosas y atrevidas propuestas en ciertas áreas periféricas de la ciudad y no en el interior del ensanche de Calvet. Los planteamientos teóricos y los proyectos de todos estos actores no siempre tuvieron éxito, pero su revisión por parte de los redactores de los Planes Generales de 1973, 1985 y 1998 favoreció la crítica de las carencias y las irregularidades del primer ensanche, e impulsó una nueva manera de operar en él.

Hasta el momento, lo cierto es que la previsión de Calvet en relación con la gran zona verde al noroeste de la ciudad ha sido imbricada en todos los planes urbanísticos posteriores, aunque con ciertas e importantes alteraciones relativas a sus límites y su forma originales. La causa de esta imbricación parece que está en la función vertebradora que tiene la zona, la única de Palma contigua al casco histórico con potencial de espacio verde y de verdadero bosque urbano, si se exceptúa el Parc de ses Estacions (de 3,7 Ha). Este está situado frente a la céntrica plaza de España, y sirve de enlace directo con el primer ensanche. Se trata, además, de un espacio ajardinado y vallado que en su momento perdió la oportunidad de transformarse en parte de un gran corredor verde (el Parc de les Vies) que arrancara de la plaza de España hasta alcanzar el polígono de Son Fuster. Por su parte, el Parc de la Mar, un parque de 9,1 Ha situado en el frente litoral bajo la catedral, no ejerce de 'pulmón' vegetal y no pertenece al ensanche. Sólo el bosque de Bellver (110 Ha) puede desempeñar eficazmente y a la vez las funciones ecológicas, recreativas, higiénico-sanitarias, estéticas y didáctico-educativas que se asignan al verde urbano, pero se trata de un espacio demasiado separado del centro de la ciudad y es poco accesible.

ACE, 15 (4.5) CC BY-ND 3.0 ES | UPC Barcelona, España | Urbanismo crítico, cartografía y evolución del verde urbano en los planes de ensanche históricos de la ciudad de Palma. DOI: http://dx.doi.org/10.5821/ace.15.45.9039 
En Palma, los cambios de criterio urbanístico operados a partir del año 1902, momento en que se comienza a ejecutar el ensanche, tienen dos sentidos. En primer lugar, uno negativo, por cuanto que las dos grandes zonas verdes previstas en el plan de Calvet, y salvaguardadas en los planes de Bennazar (1917) y de Alomar (1943), han sido sustancialmente reducidas en su extensión, cuando no parcialmente urbanizadas y colmatadas por construcciones de diversa índole. Cuando los intereses sobre el espacio de la ciudad son numerosos y distintos -los del promotor urbano y del propietario del suelo a urbanizar, pero también los del Estado, de la corporación municipal, de las comunidades vecinales o del mismo individuo vecinal-, es harto frecuente que los usos de los espacios libres como zonas verdes devengan contrarios a lo planeado en origen, y en ellos se acabe reduciendo la superficie con vegetación. Como consecuencia de esto, el espacio intraurbano acaba dominado por una textura artificial de viviendas e infraestructuras viarias que suprimen o desplazan el verde, o éste acaba encajándose no antes sino después de la actuación constructiva. Es por esto por lo que la pérdida o la rebaja de los espacios verdes, y con ella la pérdida de sus funciones ambientales, estéticas o recreativas, haya sido fuente habitual de conflictos sociales. En segundo lugar, los cambios de criterio urbanístico también tienen un sentido positivo, por cuanto que si en el año 1897 Calvet rechazaba la necesidad de establecer con precisión y con carácter definitivo la distribución espacial de toda la matriz verde en Palma, a fin de no comprometer futuras intervenciones, en la actualidad el criterio es el inverso: la renaturalización de las ciudades ha devenido un imperativo, y la normativa urbanística consagra los equipamientos verdes como una necesidad, una obligación y un derecho, de ahí que se haya llegado a un punto en el que en no pocas ciudades españolas la praxis urbanística haya tendido a restituir el verde urbano allá donde esto ha sido urbanísticamente y políticamente posible. En Palma se ha podido demostrar con el proyecto de Cuña o Falca Verda surgido del Plan General de 1985, o como en su día se demostró con una propuesta de corredor verde con criterios paisajísticos que partiera del centro de la ciudad hasta alcanzar su periferia.

De esta manera, parece que los postulados ambientalistas que se adoptaron en los primeros planes de ensanche y reforma de Palma se antojan los mismos que hoy se utilizan para justificar la necesidad del verde urbano por su papel estratégico en la regeneración urbana y adaptación al cambio climático, como recuerdan, entre otros, García-Sánchez et al. (2018) para el caso de Bilbao y Nueva York, o Howard (2009). A la vista de los resultados, el verde urbano de Palma ha sobrevivido mejor en el radio externo de la ciudad. Pero si la expansión de la urbanización hace presión sobre el medio rural, en las barriadas periféricas y ya rur-urbanas se enfrentan dos culturas, la de la ciudad y la del campo, confrontación que normalmente se satisface a favor de la primera y en perjuicio del segundo. En este sentido podemos recordar la incontestable sentencia de Harold Carter (1987) según la cual "lo que ayer era campiña silvestre, mañana será parque urbano”. Es una cuestión de tiempo que esta premonición se materialice en la práctica totalidad de los núcleos rurales del extrarradio de Palma, mientras que en su ensanche se fuerce la regeneración de las grandes zonas verdes previstas en los planes urbanísticos de la primera mitad del siglo XX, o la creación de otras nuevas.

\section{Agradecimientos}

El autor quiere expresar su agradecimiento al arquitecto y urbanista Manuel Cabellos Barreiro por sus observaciones y sugerencias en relación con los contenidos de este trabajo, así como también a las personas que lo han evaluado, contribuyendo a la mejora de su versión definitiva.

Conflicto de intereses: El autor declara que no hay conflicto de intereses. 


\section{Bibliografía}

Aleñá Guinart, J. (1916). Anteproyecto de Reforma de Palma. Palma: Tipo-Litografía de Amengual y Muntaner.

Alomar Esteve, G. (1950). La reforma de Palma. Hacia la renovación de una ciudad a través de un proceso de ordenación creativa. Palma de Mallorca, España: Imprenta Mossèn Alcover.

Alomar Esteve, G. (1961). Sociología urbanística. Madrid, España: Editorial Aguilar.

Alomar-Garau, G. y Llop-Garau, J. (2018). La isla de calor urbana de Palma (Mallorca, Islas Baleares): avance para el estudio del clima urbano en una ciudad litoral mediterránea. Boletín de la Asociación de Geógrafos Españoles, 78, 392-418. DOI: http://dx.doi.org/10.21138/bage.2404

Alomar-Garau, G.; Bauzà-Llinàs, J. (2020). Teledetección LiDAR y multiespectral para el análisis del verde urbano en una ciudad media mediterránea: Palma (Mallorca): relación con el clima a escala local. En C. Llop, M. Cervera y F. Peremiquel (Eds.), IV Congreso ISUF-H: Metrópolis en recomposición: prospectivas proyectuales en el Siglo XXI: Forma urbis y territorios metropolitanos, Barcelona, 28-30 septiembre 2020 (pp. 1-18). Barcelona: DUOT, UPC. Recuperado de: http://hdl.handle.net/2117/328612

Alonso Velasco, J. M. (1971). Ciudad y espacios verdes. Madrid, España: Servicio Central de Publicaciones. Ministerio de la Vivienda.

Anderson, K.; Hancock, S.; Casalegno, S.; Griffith, A.; Griffiths, D.; Sargentc, F.; McCallum, J.; Cox, D.T.C. y Gaston, K. J. (2018). Visualising the urban green volume: Exploring LiDAR voxels with tangible technologies and virtual models. Landscape and Urban Planning, 178, 248-260. DOI: https://doi.org/10.1016/j.landurbplan.2018.05.024

Andrés López, G. (1999). De las ordenanzas municipales al primer plan de la democracia: origen y evolución del planeamiento urbano en la ciudad de Burgos. Boletín de la Institución Fernán González, 219, 415-450. Recuperado de: http://hdl.handle.net/10259.4/2106

Bengochea, A. (2003). A hedonic valuation of urban green areas. Landscape and Urban Planning, 66, 35-41. DOI: https://doi.org/10.1016/S0169-2046(03)00093-8

Bennazar Moner, G. (1917). Memoria del Plan de Reforma de Palma. A.M.P. Palma.

Bowler, D.E.; Buyung-Ali, L.; Knight, T. M., Pullin, A. S. (2010). Urban greening to cool towns and cities: A systematic review of the empirical evidence. Landscape and Urban Planning, 97, 147-155. DOI: https://doi.org/10.1016/j.landurbplan.2010.05.006

Cabellos Barreiro, M. (2016). La Platja de Palma. Evolució històrica i planejament urbà. Palma, España: Edicions Documenta Balear.

Calvet Girona, B. (1897). Proyecto de ensanche de la Ciudad de Palma de Mallorca. Memoria. Aprobado en concurso público por R.D. de 22 de febrero de 1901. Palma, España: Tipo-Litografía de Amengual y Muntaner.

Cantarellas Camps, C. (1981). La arquitectura mallorquina desde la llustración a la Restauración. Palma, España: Institut d’Estudis Baleàrics.

ACE, 15 (4.5) CC BY-ND 3.0 ES | UPC Barcelona, España | Urbanismo crítico, cartografía y evolución del verde urbano 23 en los planes de ensanche históricos de la ciudad de Palma. DOI: http://dx.doi.org/10.5821/ace.15.45.9039 
Cantarellas Camps, C. (1984). Pedro de Alcántara Peña, maestro de obras militares (1823-1906). Palma, España: Taller Gràfic Ramon.

Capel, H. (1975). Capitalismo y morfología urbana en España. Barcelona, España: Los Libros De la Frontera.

Capel, H. (2002). La morfología de las ciudades. Tomo I: Sociedad, cultura y paisaje urbano. Barcelona, España: Ediciones del Serbal.

Carter, H. (1987). El estudio de la geografía urbana. Madrid, España: Instituto de Estudios de Administración Local.

Castro, C. M. (1860). Memoria descriptiva del ante-proyecto de ensanche de Madrid. Madrid, España: Imprenta de José C. de la Peña, Atocha 149.

Crompton, J. L. (2017). Evolution of the 'parks as lungs' metaphor: is it still relevant?. World Leisure Journal, 59(2), 105-123. DOI: https://doi.org/10.1080/16078055.2016.121117

Dana, E. D.; Vivas, S. y Mota, J. F. (2002). Urban vegetation of Almería City - a contribution to urban ecology in Spain. Landscape and Urban Planning, 59, 203-216. DOI: https://doi.org/10.1016/S0169$\underline{\text { 2046(02)00039-7 }}$

Delgado Viñas, C. (1995). Las pequeñas y medianas capitales de provincia en el proceso de modernización del sistema urbano español. Las Palmas de Gran Canaria, España: Universidad de Las Palmas de Gran Canaria. Servicio de Publicaciones.

Díez Monge, F. (1988). Ciudad jardín de Palma. Un nombre impropio para una urbanización en la costa de Mallorca a comienzos de siglo. Bolletí de la Societat Arqueològica Lulliana, 44, 307-323. Recuperado de: https://core.ac.uk/download/pdf/185516288.pdf

Estada, E. (1885). La Ciudad de Palma. Su industria, sus fortificaciones, sus condiciones sanitarias y su ensanche. Palma de Mallorca, España: Tipografía de la Viuda e Hijos de Pedro J. Gelabert.

Fadigas, L. (2017). La estructura verde en el proceso de planificación urbana. Ciudades, 12, 33-47. DOI: https://doi.org/10.24197/ciudades.12.2009.33-47

Ferrà, B. (1891). Ensanche de Palma. Boletín de la Sociedad Arqueológica Luliana, Año VII, Tomo IV(139), 135-140.

Forteza Piña, G. (1921). L'art de construir les ciutats i la reforma de Palma. Palma, España: Amengual i Muntaner.

Forteza Piña, G. (1931). La urbanització de Palma. Ciutat antiga i ciutat moderna. Palma, España: Estampa de Soler Prats.

Forteza Piña, G. (1934). L'esdevenidor de la nostra ciutat. Urbanisme mínim. Palma, España: Estampa de Soler Prats.

Fröbel, F. (1902/1999). La educación del hombre. Alicante: Biblioteca Virtual Miguel de Cervantes. Publicación original: Nueva York, D. Appleton y Compañía, 1902. Traducida del alemán por J. Abelardo Núñez; nueva edición anotada por W.N. Hailmann.

ACE, 15 (4.5) CC BY-ND 3.0 ES | UPC Barcelona, España | Urbanismo crítico, cartografía y evolución del verde urbano en los planes de ensanche históricos de la ciudad de Palma. DOI: http://dx.doi.org/10.5821/ace.15.45.9039 
García-Bellido, J. (2006). Pascual Madoz e Ildefonso Cerdà, dos pioneros en la epifanía de la urbanística. ACE: Arquitectura, Ciudad y Entorno, 1(1), 4-28. DOI: http://dx.doi.org/10.5821/ace.v1i1.2337

García-Lorca, A. M. (1989). El parque urbano como espacio multifuncional: origen, evolución y principales funciones. Paralelo, 37(13), 105-111. Recuperado de https://www.researchgate.net/publication/2816614

García-Sánchez, F.; Soleckib, W. D. y Ribalaygua, C. (2018). Climate change adaptation in Europe and the United States: A comparative approach to urban green spaces in Bilbao and New York City. Land Use Policy, 79, 164-173. DOI: https://doi.org/10.1016/j.landusepol.2018.08.010

Gilbert, O. L. (1991). The ecology of urban habitats. London, United Kingdom: Chapman \& Hall.

Gómez-Lopera, F. (2005). Las zonas verdes como factor de calidad de vida en las ciudades. Ciudad y Territorio: Estudios territoriales, 37(144), 417-436. Recuperado de: https://recyt.fecyt.es/index.php/CyTET/article/view/75554

Horrach Estarellas, B. (2013). Nuevas pautas de regeneración de los destinos turísticos maduros. Tras más de cien años de construcción de Platja de Palma. ACE: Arquitectura, Ciudad y Entorno, 9(25), 349372. DOI: http://dx.doi.org/10.5821/ace.9.25.3631

Howard, J. (2009). Climate Change Mitigation and Adaptation in Developed Nations: A Critical Perspective on the Adaptation Turn in Urban Climate Planning. En S. Davoudi, Crawford, J. y Mehmood, A. (Eds.), Planning for Climate Change. Strategies for Mitigation and Adaptation for Spatial Planners (pp. 19-32). London, United Kingdom: Earthscan Publishing.

Hoyle, H; Hitchmough, J. y Jorgensen, A. (2017). All about the 'wow factor'? The relationships between aesthetics, restorative effect and perceived biodiversity in designed urban planting. Landscape and Urban Planning, 164, 109-123. DOI: https://doi.org/10.1016/j.landurbplan.2017.03.011

IBESTAT, Institut d'Estadística de les Illes Balears (2020a). Padrón (cifras de población). Conselleria de Model Econòmic, Turisme i Treball, Govern de les Illes Balears.

IBESTAT, Institut d'Estadística de les Illes Balears (2020b). Censos de población. Censos históricos. Conselleria de Model Econòmic, Turisme i Treball, Govern de les Illes Balears.

Ladaria Bañares, M. D. (1992). El ensanche de Palma. Planteamiento del tema, problemática, construcción y valoracion de un nuevo espacio urbano, 1868-1927. Palma, España: Ajuntament de Palma.

Magrinyà, F. (2009). El ensanche y la reforma de Ildefons Cerdà como instrumento urbanístico de referencia en la modernización urbana de Barcelona. Scripta Nova. Revista electrónica de geografía y ciencias sociales, 13(296). Recuperado de http://www.ub.edu/geocrit/sn/sn-296/sn-296-3.htm

Mansergas Sellens, O. (2015). El ensanche de Santa Catalina: un urbanismo defensivo. En P. Rodríguez (Ed.), Proceedings-Modern Age Fortifications of the Western Mediterranean coast-Defensive Architecture of the Mediterranean (pp. 207-214). Valencia, España: Universitat Politècnica de València. DOI: http://dx.doi.org/10.4995/FORTMED2015.2015.1764

Matesanz Parellada, Á. (2009). El suelo en la legislación urbanística española. Boletín CF+S, 51, 7-61.

ACE, 15 (45) CC BY-ND 3.0 ES | UPC Barcelona, España | Urbanismo crítico, cartografía y evolución del verde urbano en los planes de ensanche históricos de la ciudad de Palma. DOI: http://dx.doi.org/10.5821/ace.15.45.9039 
Mayol Amengual, J. (2010). L'arquitectura escolar de Guillem Forteza, 1917-1943 (Tesis doctoral). Universitat Politècnica de Catalunya, Barcelona. Recuperado de: https://www.tdx.cat/handle/10803/77767\#page=413

Miranda González, M. A. (2006). Pedro García Faria, ingeniero de Caminos (y arquitecto). Scripta Nova. Revista electrónica de geografía y ciencias sociales, X(221).

Muga Fernández, M. (1980). La utilización de los espacios verdes en la ciudad de Logroño. Cuadernos de investigación geográfica, 6, 71-93. DOI: http://dx.doi.org/10.18172/cig.882

Nowak, D. J.; Civerolo, K. L.; Rao, S. T.; Sistla, S.; Luley, C. J. y Crane, D. E. (2000). A modelling study of the impact of urban trees on ozone. Atmospheric Environment, 34, 1601-1613. DOI: https://doi.org/10.1016/S1352-2310(99)00394-5

Ochoa, J. M. (2009). Ciudad, vegetación e impacto climático. Vilafranca del Penedés, España: Erasmus Ediciones.

Oliver, M. dels Sants (24 de enero de 1893). Banquete en honor de Don Eusebio Estada. La Almudaina.

Priego González de Canales, C. (2011). Naturaleza y sociedad. El valor de los espacios verdes urbanos. Madrid, España: Ministerio de Medio Ambiente y Medio Rural y Marino.

Ribas Piera, M. (1973). Presentación y síntesis del Plan general de ordenación urbanística de Palma de Mallorca, redactado en 1970. Cuadernos de Arquitectura, 98, 47-53. Recuperado de https://www.raco.cat/index.php/CuadernosArquitecturaUrbanismo/article/view/111679/161004

Rodríguez-Avial, L. (1980). El sistema de espacios libres en una ciudad y su planeamiento (Tesis doctoral). Escuela Técnica Superior de Arquitectura de Madrid, Madrid. Recuperado de: http://oa.upm.es/30584/

Rodríguez Mas, A. (1964). El hombre y la ciudad. Segovia, España: Imp. Provincial.

Santiago Ramos, J. (2008). La naturaleza en la ciudad: perspectivas teóricas y metodológicas para el estudio de la funcionalidad ambiental del espacio libre. Sevilla, España: Consejería de Obras Públicas y Transportes. Dirección General de Planificación. Junta de Andalucía.

Salvo Tierra, A. E. y García-Verdugo, J. C. (Eds.) (1994). Naturaleza urbanizada. Estudios sobre el verde en la ciudad. Málaga, España: Universidad de Málaga/Debates.

Santaner Marí, J. (1967). Historia del arrabal de Santa Catalina. Palma de Mallorca, España: Gráficas Miramar.

Salvati, A.; Roura, H. y Cecere, C. (2016). Urban heat island prediction in the mediterranean context: An evaluation of the urban weather generator model. ACE: Architecture, City and Environment, 11(32), 135156. DOI: http://dx.doi.org/10.5821/ace.11.32.4836

Seguí Aznar, M. (1981). Propuestas urbanísticas de Gaspar Bennazar. Boletín de la Sociedad Arqueológica Luliana, 38, 475-490.

Seguí Aznar, M. (1985-87). Planteamientos teóricos y realización práctica del plan Calvet. Mayurqa, 21, 393-411.

ACE, 15 (4.5) CC BY-ND 3.0 ES | UPC Barcelona, España | Urbanismo crítico, cartografía y evolución del verde urbano 26 en los planes de ensanche históricos de la ciudad de Palma. DOI: http://dx.doi.org/10.5821/ace.15.45.9039 
Seguí Aznar, M. (1990). Arquitectura contemporánea en Mallorca (1900-1947). Palma, España: Universitat de les Illes Balears y Col-legi Oficial d'Arquitectes de les Balears.

Seguí Aznar, M. (2000). Urbanisme i arquitectura a les Balears. Segle XX. Palma, España: Edicions Documenta Balear.

Sureda Blanes, J. y Alomar Esteve, G. (1946). Guillermo Forteza. Arquitecto. Palma: Imprenta Mossén Alcover.

Sukopp, H. y Werner, P. (1989). Naturaleza en las ciudades. Madrid, España: Dirección General de Medio Ambiente.

Terán Troyano, F. de (1996). Evolución del planeamiento urbanístico (1846-1996). Ciudad y Territorio: Estudios Territoriales, XXVIII(107-108), 167-184. Recuperado de http://oa.upm.es/11491

Tous Meliá, J. (2009). Palma a través de la cartografía (1596-1902). Palma, España: Ajuntament de Palma.

Ward, S. (2017). Searching for effective and democratic town planning: the international travels of Sir Ernest Simon, 1936-1943, Planning Perspectives, 32(3), 353-371.

DOI: https://doi.org/10.1080/02665433.2017.1286516

Zaforteza Musoles, D. (1954). La ciudad de Mallorca. Ensayo histórico-toponímico. Tomo II. Palma, España: Ajuntament de Palma.

Zaforteza Musoles, D. (1988). La ciudad de Mallorca. Ensayo histórico-toponímico. Tomo V. Palma, España: Ajuntament de Palma. 